\title{
AVALIAÇÃO DO POTENCIAL FISIOLÓGICO DE SEMENTES DE RABANETE (Raphanus sativus L.)
}

\author{
Virgínia ARantes Ferreira Carpi
}

Dissertação apresentada à Escola Superior de Agricultura "Luiz de Queiroz", Universidade de São Paulo, para obtenção do título de Mestre em Agronomia, Área de Concentração: Fitotecnia.

P IR A C I C A B A

Estado de São Paulo - Brasil Junho - 2005 


\title{
AVALIAÇÃO DO POTENCIAL FISIOLÓGICO DE SEMENTES DE RABANETE (Raphanus sativus L.)
}

\author{
VIRGínIA ARANTES FERREIRA CARPI
}

Engenheiro Agrônomo

Orientador: Prof. Dr. JULIO MARCOS FILHO

Dissertação apresentada à Escola Superior de Agricultura "Luiz de Queiroz", Universidade de São Paulo, para obtenção do título de Mestre em Agronomia, Área de Concentração: Fitotecnia.

$P|R A C| C A B A$

Estado de São Paulo - Brasil

Junho - 2005 
Dados Internacionais de Catalogação na Publicação (CIP) DIVISÃO DE BIBLIOTECA E DOCUMENTAÇÃO - ESALQ/USP

Carpi, Virgínia Arantes Ferreira

Avaliação do potencial fisiológico de sementes de rabanete (Raphanus sativus L.) Virgínia Arantes Ferreira Carpi. - - Piracicaba, 2005.

$77 \mathrm{p}$.

Dissertação (mestrado) - - Escola Superior de Agricultura Luiz de Queiroz, 2005.

Bibliografia.

1. Condutividade elétrica 2. Controle de qualidade 3. Fisiologia vegetal 4. Lixiviação 5. Potássio 6. Rabanete 7. Teste de sementes I. Título

CDD 635.15

"Permitida a cópia total ou parcial deste documento, desde que citada a fonte - O autor" 
À minha família pela dedicação,

compreensão, carinho e apoio...

Ofereço

Aos meus pais Lélia e Mario, aos meus avós Alice (in memoriam) e Eloy, aos meus irmãos Sílvia e Mário, aos meus cunhados Valéria e Carlos, aos meus sobrinhos Amanda, Beatriz, Letícia e Rafael por todo amor incondicional... 


\section{AGRADECIMENTOS}

À Escola Superior de Agricultura "Luiz de Queiroz" (USP/ESALQ) pela oportunidade de realizar o curso de Mestrado.

Ao Professor Dr. Julio Marcos Filho pela orientação, apoio, confiança e dedicação durante estes anos.

Aos meus pais Mario e Lélia, meus irmãos Sílvia e Mário, meus cunhados Carlos e Valéria, meus avós Eloy e Alice (in memoriam) por todo amor, apoio, compreensão, paciência e presença constante em minha vida.

A Fundação de Amparo à Pesquisa do Estado de São Paulo (FAPESP) pela concessão de Bolsa de Mestrado.

Aos Professores Dr. Sílvio Moure Cícero e Dr. Walter Rodrigues da Silva pela atenção e ensinamentos durante o curso.

Aos professores do Departamento de Produção Vegetal da ESALQ/USP pela oportunidade de aprendizado, sugestões e auxílio durante a elaboração deste trabalho.

Às Engenheiras Agrônomas Ana Dionísia L.C. Novembre, Helena M.C.P. Chamma e Maria Heloísa D. Moraes, pela colaboração e sugestões durante a condução do trabalho.

À Engenheira Agrônoma Nilza Patrícia Ramos, pela amizade, apoio e dedicação.

Aos amigos conquistados nessa fase de minha vida, em especial: Adriana Pedroso, Ariana, Cibele, Felipe, Helena Barone, Janete, Magali, Marcelo Pedroni, Maria Carolina, Otávio, Roseli, Sérgio, Silvana e Walnice pelo companheirismo, apoio, paciência e compreensão nos períodos difíceis e também pelos valiosos momentos compartilhados. 
Aos amigos de longa data Camila, Cláudia, Giuliana, Michele, Vanessa e Fábio, que permanecem ao meu lado, contribuindo com sua atenção e dedicação em todos os momentos.

Aos colegas do Laboratório de Sementes Angélica, Ana Lúcia, Ebert, Eniel, José Luis e Maria Cristina pela convivência e todo o auxílio técnico-científico durante o trabalho, além do agradável convívio.

Às secretárias Ilze Helena C.G. das Neves e Luciane Aparecida Lopes pela amizade e auxílio prestados durante o curso

Ao funcionário João E. Jabur Filho por todo apoio e auxílio na condução de experimentos. Também à Flávia Oliveira e Nilda pela colaboração na limpeza do laboratório e Pavilhão de Tecnologia de Sementes.

A todos que direta ou indiretamente contribuíram para a execução deste trabalho. 


\section{SUMÁRIO}

Página

RESUMO

SUMMARY

1 INTRODUÇÃO

2 REVISÃO DE LITERATURA...........................................................

2.1 Avaliação do vigor de sementes..............................................................

2.1.1 Envelhecimento acelerado....................................................................

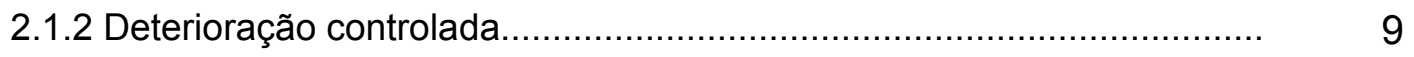

2.1.3 Condutividade elétrica........................................................................ 11

2.1.4 Lixiviação de potássio .......................................................................... 16

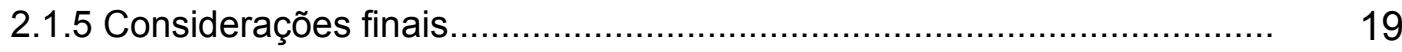

3 MATERIAL E MÉTODOS....................................................................... 20

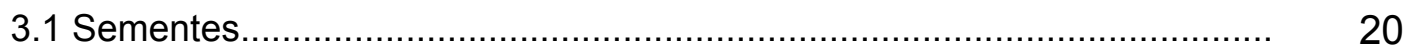

3.2 Determinação do grau de umidade ......................................................... 21

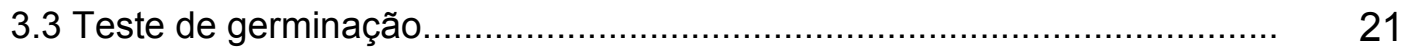

3.4 Primeira contagem de germinação ....................................................... 22 
3.5 Envelhecimento acelerado (procedimento tradicional)........................... 22

3.6 Envelhecimento acelerado (solução saturada de $\mathrm{NaCl}$ )............................ 23

3.7 Deterioração controlada.............................................................. 23

3.8 Condutividade elétrica........................................................................ 24

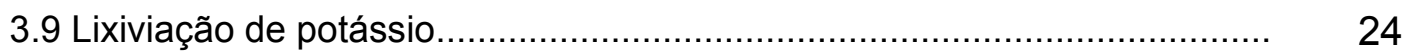

3.10 Emergência de plântulas.................................................................... 26

3.11 Procedimento estatístico .............................................................. 26

4 RESULTADOS E DISCUSSÃO......................................................... 30

4.1 Germinação, primeira contagem, emergência de plântulas e 30 determinação do grau de umidade...........................................................

4.2 Envelhecimento acelerado (procedimento tradicional)......................... 32

4.3 Envelhecimento acelerado (solução saturada de $\mathrm{NaCl}$ ).......................... 35

4.4 Deterioração controlada................................................................ 38

4.5 Condutividade elétrica........................................................................ 41

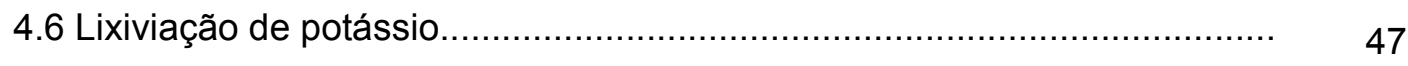

4.7 Considerações finais....................................................................................... 52

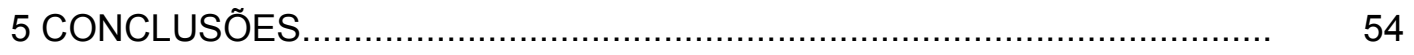

REFERÊNCIAS BIBLIOGRÁFICAS ...................................................... 55 


\section{AVALIAÇÃO DO POTENCIAL FISIOLÓGICO DE SEMENTES DE RABANETE (Raphanus sativus L.)}

Autora: VIRGÍNIA ARANTES FERREIRA CARPI

Orientador: Prof. Dr. JULIO MARCOS FILHO

\section{RESUMO}

A intensificação da produção brasileira tem contribuído para a redução da importação de sementes de hortaliças devido, principalmente, à atuação de empresas multinacionais. O elevado valor comercial e o aumento da utilização de sementes híbridas têm justificado o uso de sementes de qualidade diferenciada, cuja oferta tem sido crescente. Neste contexto, o presente trabalho teve como objetivo estudar a eficiência de diferentes métodos para a avaliação do potencial fisiológico de sementes de rabanete (Raphanus sativus L.), visando à identificação dos mais promissores para a utilização em programas de controle de qualidade. Utilizaram-se lotes de três cultivares de rabanete, a saber: Gigante Siculo (4 lotes), Cometa (3 lotes) e Saxa (2 lotes). A avaliação da viabilidade e do vigor das sementes foi realizada mediante a 
condução de testes de germinação, primeira contagem de germinação, envelhecimento acelerado, deterioração controlada, condutividade elétrica, lixiviação de potássio e emergência de plântulas, sendo estudadas variações nos procedimentos para condução dos testes de envelhecimento acelerado, deterioração controlada, condutividade elétrica e lixiviação de potássio.

Concluiu-se que o teste de envelhecimento acelerado com procedimento tradicional, destacando o binômio temperatura/período de exposição de $41^{\circ} \mathrm{C} / 48$ horas, é suficientemente sensível para detectar diferenças entre lotes de sementes de rabanete. Os testes de condutividade elétrica e lixiviação de potássio podem constituir alternativas promissoras para a avaliação do vigor de sementes de rabanete, mas há necessidade de estudos adicionais para determinação dos procedimentos mais adequados para sua condução. 


\title{
EVALUATION OF THE PHYSIOLOGICAL POTENTIAL OF RADISH SEEDS (Raphanus sativus L.)
}

\author{
Author: VIRGÍNIA ARANTES FERREIRA CARPI \\ Adviser: Prof. Dr. JULIO MARCOS FILHO
}

\section{SUMMARY}

The increase in Brazilian production seeds has contributed to reduce the import of vegetable seeds mainly by international companies. The commercial value and the preferential use of hybrids instead of open pollinated cultivars has justified the demand for high quality seeds. In this context, this research was conducted with the objective to study the efficacy of different methods to evaluate the physiological potential of radish (Raphanus sativus L.) seeds. Three cultivars were evaluated: Siculo Giant (four lots), Comet (three lots) and Saxa (two lots). Seed viability and vigor seed lots were determined by germination, germination first count, accelerated aging, controlled deterioration, electrical conductivity, potassium leachate and seedling emergence tests, including alternative procedures for the accelerated aging, controlled deterioration, electrical conductivity and potassium leachate tests. It was concluded that traditional accelerated aging (48 hours/ $41^{\circ} \mathrm{C}$, was sensitive to identify different levels of physiological potential in the studied lots. The electrical conductivity and potassium leachate are promising 
options for vigor testing of radish seeds, but research is still necessary to define the most effective procedures to perform these tests. 


\section{INTRODUÇÃO}

A avaliação do potencial fisiológico é componente essencial de um programa de controle de qualidade de sementes, fornecendo informações para a deteç̧ão e solução de problemas durante o processo produtivo e, também, sobre o desempenho das sementes. O teste de germinação é utilizado rotineiramente, mas, por ser conduzido sob condições ambientais favoráveis, pode fornecer resultados que superestimam o potencial fisiológico das sementes. Por esse motivo, foram desenvolvidos testes de vigor que retratam o comportamento das sementes sob maior amplitude de condições ambientais, complementando as informações obtidas no teste de germinação.

$\mathrm{Na}$ atualidade, alguns testes de vigor são amplamente empregados na avaliação do potencial fisiológico de sementes de grandes culturas, como por exemplo, o de envelhecimento acelerado para sementes de soja e o de condutividade elétrica para as sementes de ervilha. Porém, poucos estudos têm sido conduzidos sobre o emprego de testes de vigor para avaliação do potencial fisiológico de sementes de hortaliças. O desenvolvimento de novos testes, o aprimoramento e a padronização dos disponíveis para sementes dessas espécies, é importante, considerando que o valor comercial de sementes de hortaliças vem aumentando (McDonald, 1998). Segundo Marcos Filho (1999b), as informações sobre o vigor são fundamentais para sementes de elevado valor comercial, como as hortaliças, porque apresentam menores quantidades de reservas e são sensíveis a alterações resultantes da deterioração após a maturidade fisiológica. Por este motivo, comumente são armazenadas em embalagens herméticas ou sob temperatura e/ou umidade relativa reduzidas. 
O rabanete (Raphanus sativus L.), da família Brassicaceae, apesar de ser uma cultura que não ocupa extensa área cultivada no Brasil, está presente em grande número de pequenas propriedades dos cinturões verdes com grande diversidade de cultivo de hortaliças. Uma característica da cultura de rabanete é poder ser usada entre outras de ciclo mais longo, com épocas definidas de semeadura, pois, além de ser relativamente rústica, apresenta ciclo muito curto (cerca de 30 dias), com retorno rápido (Minami et al., 1998). Poucos trabalhos têm sido efetuados com essa cultura, havendo carência de informações sobre seu cultivo, principalmente no Brasil. O rabanete é uma hortaliça que ocupa um lugar proeminente na olericultura brasileira e suas sementes possuem elevado valor comercial. $\mathrm{Na}$ atualidade, existem poucos trabalhos a respeito da utilização de testes de vigor para estimar o potencial fisiológico de sementes dessa espécie (Menezes et al., 2001). Portanto, há uma demanda por informações que possam fornecer subsídios e apoio aos programas de controle de qualidade.

Dessa forma, o presente trabalho teve como objetivo básico estudar, comparativamente, a eficiência de diferentes métodos na avaliação do potencial fisiológico de sementes de rabanete (Raphanus sativus L.), para a obtenção de informações que permitam indicar os mais promissores para utilização em programas de controle de qualidade. 


\section{REVISÃO DE LITERATURA}

\subsection{Avaliação do vigor de sementes}

A produção brasileira de sementes de hortaliças ganhou maior impulso no final dos anos 1990, principalmente, pela atuação de empresas multinacionais no mercado. Essa situação decorreu da busca de novos conhecimentos para a produção de sementes de hortaliças, em parte incorporados aos disponíveis para espécies de grandes culturas, em que o grau tecnológico da produção nacional é comparável ao predominante em países considerados mais desenvolvidos. Inicialmente, as pesquisas voltaram-se, de modo mais intensivo, para a introdução de materiais genéticos adaptados às condições de produção do Brasil. Após a fase da adequação inicial de cultivares, sistemas de produção, embalagens e comercialização, tem emergido a demanda por pesquisas que forneçam informações capazes de permitir apoio ao controle de qualidade durante as diferentes etapas do processo de produção de sementes. Desta maneira, verificam-se esforços direcionados ao estudo de métodos para estimativa do vigor de sementes.

Para a Association of Official Seed Analysts - AOSA (1983), o vigor de sementes compreende um conjunto de características que determinam 0 potencial para a emergência e o rápido desenvolvimento de plântulas normais, sob ampla diversidade de ambiente. Marcos Filho (1999a) considera que os objetivos básicos dos testes de vigor são: a identificação de diferenças no potencial fisiológico de lotes com germinação semelhante; distinguir, com 
segurança, lotes de alto e baixo vigor; classificar lotes em diferentes níveis de vigor, de maneira comparável à emergência de plântulas em campo, resistência ao transporte e potencial de armazenamento.

Lotes de sementes que apresentam germinação semelhante, freqüentemente, exibem comportamentos distintos durante o armazenamento e/ou em campo. As diferenças de vigor entre lotes podem ser explicadas pelo fato de que as primeiras alterações nos processos bioquímicos associados à deterioração ocorrem, em geral, antes que se manifestem os declínios significativos na capacidade germinativa (Delouche \& Baskin, 1973). Por essa razão, o uso de testes de vigor é de grande importância no monitoramento do potencial fisiológico das sementes, a partir da maturidade (Dias \& Marcos Filho, 1995).

Vieira \& Carvalho (1994) consideraram que cada tipo de teste tem sua eficiência na avaliação do vigor de sementes de determinadas culturas, não existindo, até o momento, nenhum teste de vigor que possa ser recomendado como padrão para todas ou mesmo para uma única espécie, uma vez que o vigor reflete a manifestação de várias características. A Association of Official Seed Analysts - AOSA (1983), enfatizou a importância da precisão dos procedimentos utilizados para a condução de testes de vigor, dos problemas enfrentados para a padronização dos procedimentos e a apresentação dos resultados. Ressaltou que o principal desafio das pesquisas sobre testes de vigor está na identificação de parâmetros adequados, comuns à deterioração de sementes, de forma que, quanto mais próximo da maturidade fisiológica ou mais distante da perda da capacidade de germinação estiver o parâmetro avaliado, mais sensível deveria ser o teste, fornecendo assim informações complementares às obtidas no teste de germinação.

Além da necessidade de padronização de metodologias e interpretação de resultados, os testes de vigor devem apresentar relação com a emergência de plântulas em campo, rapidez, objetividade, simplicidade, baixo custo e reprodutibilidade (Delouche, 1976; AOSA, 1983; TeKrony, 1983). 
A padronização dos testes de vigor torna-se fundamental à medida que as técnicas de manejo cultural tornam-se mais sofisticadas, evidenciando a necessidade do uso de sementes de potencial fisiológico elevado (Perry, 1981; McDonald, 1998). Os testes de vigor são cada vez mais relevantes para sementes de hortaliças, viabilizando a prática de semeadura de precisão, a eliminação do desbaste e a obtenção de uniformidade de desenvolvimento e maturação de plantas. Para tanto, as sementes devem exibir potencial fisiológico elevado, tornando necessário o emprego rotineiro de testes de vigor em programas de controle de qualidade (Hampton \& Coolbear, 1990).

Segundo Marcos Filho (1999b), para sementes de elevado valor comercial, como as de hortaliças, as informações sobre o vigor são sempre importantes. O cultivo dessas espécies, realizado de maneira intensiva, deve ser estabelecido com sementes de elevado potencial fisiológico, germinando rápida e uniformemente, permitindo, para espécies em que a produção comercial envolve o transplante de mudas, a utilização de plantas com tamanho e qualidade uniformes, com reflexos no futuro desenvolvimento da cultura e, possivelmente, na produção final.

Segundo Globirson (1981), a uniformidade de emergência é muito importante no cultivo de hortaliças em razão do alto custo das sementes e da mão-de-obra exigida durante o seu cultivo. Em determinadas culturas, como a da alface, a desuniformidade na emergência pode resultar na necessidade de serem efetuadas colheitas sucessivas e acarretar irregularidade de tamanho do produto colhido (Gray, 1976; Wurr \& Fellous, 1983).

Como o vigor da semente é função de um conjunto de características que determinam o potencial para emergência rápida e uniforme de plântulas normais sob ampla diversidade de condições ambientais (AOSA, 1983), a utilização de um único teste de vigor, seja este fisiológico, bioquímico ou de resistência a estresse, pode fornecer informações incompletas, mesmo para uma única espécie, quando o objetivo é avaliar o potencial de desempenho das sementes sob condições ambientais diversas (Hampton \& Coolbear, 1990). Por 
esse motivo, segundo Marcos Filho (1999b), a tendência predominante é a combinação de resultados de diferentes testes de vigor, considerando a finalidade do uso dos resultados e as limitações de cada teste.

A seguir, serão efetuados comentários sobre os testes de envelhecimento acelerado, deterioração controlada, condutividade elétrica e lixiviação de potássio, enfatizando as informações já obtidas para sementes de hortaliças e os principais fatores que afetam seus resultados.

\subsubsection{Envelhecimento acelerado}

O teste de envelhecimento acelerado é um dos mais utilizados para estimar o vigor de sementes (Ferguson-Spears, 1995). Tem como princípio o fato de que a taxa de deterioração das sementes é afetada consideravelmente pela exposição a níveis elevados de temperatura e umidade relativa do ar, considerados os fatores ambientais preponderantes na intensidade e na velocidade de deterioração. Sob essas condições, sementes mais vigorosas deterioram-se mais lentamente (Marcos Filho, 1999a).

A seqüência hipotética do processo de deterioração da semente envolve a degradação das membranas celulares, redução das atividades respiratórias e biossintéticas, redução da velocidade de germinação, redução do potencial de conservação durante o armazenamento, menor taxa de crescimento e desenvolvimento, menor uniformidade, maior sensibilidade às adversidades do ambiente, redução da emergência de plântulas em campo, aumento da ocorrência de plântulas anormais e perda do poder germinativo (Delouche \& Baskin, 1973). O teste de envelhecimento acelerado está relacionado ao potencial de conservação das sementes e, por esse motivo, poderia ser considerado como um dos mais sensíveis para avaliação do vigor, entre os disponíveis (Marcos Filho, 1999a). 
Foram conduzidos alguns trabalhos utilizando o teste de envelhecimento acelerado para sementes de hortaliças; por exemplo, Piana et al. (1995) concluíram que, dentre os testes estudados, o envelhecimento acelerado foi um dos que apresentou relação mais estreita com a emergência de plântulas de cebola em campo e obtenção de mudas vigorosas, além de identificar lotes com diferentes níveis de vigor. Em estudo conduzido com sementes de cenoura, Martins et al. (1996) constataram que os resultados desse teste se relacionou aos da emergência de plântulas em campo. Informações semelhantes foram obtidas com sementes de pepino, cenoura e melancia (Trigo \& Trigo, 1995a,b,c).

Diversos são os fatores que afetam o comportamento das sementes durante o teste; a interação temperatura/período de exposição é um dos mais pesquisados. Alguns autores se dedicaram ao estudo dessa interação, indicando para sementes de alface, $41^{\circ} \mathrm{C} / 72 \mathrm{~h}$ (TeKrony, 1995); berinjela, $41^{\circ} \mathrm{C} / 48 \mathrm{~h}$ (Bhéring et al., 2001b); brócolos, $45^{\circ} \mathrm{C} / 48 \mathrm{~h}$ (Tebaldi et al., 1999); cebola, $41^{\circ} \mathrm{C} / 72 \mathrm{~h}$ (Idiarte, 1995; TeKrony, 1995) e $42^{\circ} \mathrm{C} / 48 \mathrm{~h}$ (Piana et al., 1995); cenoura, $42^{\circ} \mathrm{C} / 24 \mathrm{~h}$ (Barbedo et al., 2000) e $41^{\circ} \mathrm{C} / 48 \mathrm{~h}$ (Rodo et al., 2000); maxixe, $41^{\circ} \mathrm{C} / 48 \mathrm{~h}$ (Silva et al., 1998); melancia, $41^{\circ} \mathrm{C} / 48 \mathrm{~h}$ (Bhéring et al., 2001a); melão, $42^{\circ} \mathrm{C} / 48 \mathrm{~h}$ (Cano-Rios et al., 2000); pimentão, $41^{\circ} \mathrm{C} / 72 \mathrm{~h}$ (TeKrony, 1995; Panobianco \& Marcos Filho, 1999); quiabo, $42^{\circ} \mathrm{C} / 72$ e $96 \mathrm{~h}$ (Lima et al., 1997), $41^{\circ} \mathrm{C} / 72 \mathrm{~h}$ (Dias et al., 1998); rabanete, $45^{\circ} \mathrm{C} / 48 \mathrm{~h}$ (Delouche \& Baskin, 1973); tomate, $42^{\circ} \mathrm{C} / 72 \mathrm{~h}$ (Nascimento et al., 1993).

No teste de envelhecimento acelerado, as diferenças na absorção de água pelas sementes expostas à atmosfera úmida, podem levar a variações acentuadas no grau de umidade ao final do período de envelhecimento. Alguns estudos conduzidos com espécies de sementes relativamente pequenas, como as de hortaliças, têm apresentado resultados menos consistentes devido à variação muito acentuada no grau de umidade das amostras após o período de envelhecimento. Powell (1995) observou diferentes graus de umidade, de 11,8 a $24,0 \%$, no envelhecimento acelerado a $45^{\circ} \mathrm{C} / 24 \mathrm{~h}$, a $100 \%$ de umidade relativa 
do ar, sendo que a germinação após o período do teste foi inversamente proporcional ao grau de umidade atingido; desta maneira, lotes que absorveram água mais rapidamente, alcançando grau de umidade mais elevado, após a exposição às condições do teste, apresentaram germinação inferior, indicando maior intensidade de deterioração, em relação aos que absorveram água mais lentamente.

A substituição da água por soluções saturadas (SSAA - "Saturated Salt Accelerated Aging") vem sendo pesquisada como método alternativo para o teste de envelhecimento acelerado. Dependendo da solução utilizada, são obtidos níveis diferentes de umidade relativa do ar, permitindo adequar a taxa de absorção de água, a velocidade e a intensidade de deterioração da semente. Jianhua \& McDonald (1996) trabalharam com sementes de Impatiens wallerana Hook, utilizando três soluções saturadas de sais, para obterem diferentes umidades relativas ( $\mathrm{KCl}-87 \% \mathrm{UR}, \mathrm{NaCl}-76 \% U \mathrm{U}$ e $\mathrm{NaBr}-55 \%$ UR), e observaram eficiência desse método para retardar a absorção de água das sementes pequenas, no teste de envelhecimento acelerado.

Em pesquisa desenvolvida com sementes de pimentão, Panobianco \& Marcos Filho (1999) verificaram que as sementes atingiram grau de umidade das sementes menor e mais uniforme após o envelhecimento com uso de solução saturada de $\mathrm{NaCl}$, observando vantagens na utilização desse procedimento para sementes pequenas, em relação ao procedimento convencional. A taxa de deterioração foi menos acentuada e, os resultados, menos drásticos e mais uniformes, além de possibilitar uma melhor identificação de lotes com diferentes níveis de potencial fisiológico. Resultados consistentes com o uso desse procedimento para a avaliação do vigor de sementes de hortaliças foram obtidos por Ramos et al. (2004) com rúcula; Rodo \& Marcos Filho (2001a), com cebola; Rodo et al. (2000), com cenoura; Bennett et al. (1998), com milho doce; Bhéring et al. (2000), com pepino; Panobianco \& Marcos Filho (1999), com pimentão; e Panobianco \& Marcos Filho (2001a), com tomate. 
O teste de envelhecimento acelerado tem sido estudado para diversas espécies, inclusive para hortaliças, visando sua padronização; porém as informações são escassas para sementes de rabanete.

\subsubsection{Deterioração controlada}

O teste de deterioração controlada segue o mesmo princípio do envelhecimento acelerado; porém, em vez do uso de ambientes com alta umidade relativa do ar, são avaliadas amostras de sementes com teor de água ajustado e semelhante, com o objetivo de conferir maior uniformidade ao teste e, conseqüentemente, padronização mais efetiva, principalmente para espécies que produzem sementes de menor tamanho. De acordo com Powell (1995), as diferenças na velocidade e intensidade de absorção de água por amostras de sementes, no teste de envelhecimento acelerado, podem ocasionar variações acentuadas no grau de umidade, especialmente em espécies que produzem sementes relativamente pequenas, o que geralmente não ocorre no teste de deterioração controlada.

A deterioração é mais rápida quando as sementes são armazenadas com elevado teor de água, em ambiente com alta temperatura (Powell, 1995). A comparação da resposta de vários lotes seria possível através do controle preciso da temperatura ou do grau de umidade das sementes, sendo todos os lotes expostos de maneira uniforme ao mesmo grau de envelhecimento ou deterioração. Segundo essa pesquisadora, no teste de envelhecimento acelerado, as diferenças na absorção da água, a partir da atmosfera úmida, podem originar variações acentuadas no grau de umidade das amostras, o que não tem ocorrido no teste de deterioração controlada, especialmente para espécies de sementes pequenas.

Neste teste, a deterioração é provocada através do ajuste do grau de umidade das sementes para, no mínimo, 15,5\%, previamente à instalação do 
teste. As sementes umedecidas são acondicionadas em recipientes herméticos e mantidas em banho-maria, sob 40 a $45^{\circ} \mathrm{C}$ constantes, durante período préestabelecido; em seguida, são colocadas para germinar. A porcentagem de plântulas normais é considerada proporcional ao vigor das sementes (Torres, 2002).

De acordo com Marcos Filho et al. (2001), no teste de deterioração controlada, o efeito do teor de água sobre a deterioração das sementes é direto, em contraste ao que se verifica no teste de envelhecimento acelerado. Isto se verifica porque o teste de deterioração controlada é conduzido com amostras que possuem o mesmo teor de água, resultando na exposição das sementes a condições uniformes e, conseqüentemente, padronização mais efetiva, principalmente para espécies que produzem sementes de menor tamanho, como as hortaliças.

A etapa de ajuste do grau de umidade das sementes é tida como crítica na condução do teste de deterioração controlada, podendo acelerar a deterioração das sementes, principalmente se a hidratação for muito rápida e a temperatura inadequada. Nesse sentido, Rosseto et al. (1995) recomendam que o processo seja lento e, para isso, o melhor meio de hidratação controlada seria a utilização do umedecimento das sementes através do método da atmosfera úmida, a $20^{\circ} \mathrm{C}$.

A deterioração controlada é um teste relativamente simples, não exigindo conhecimentos sofisticados, investimentos significativos e não apresenta dificuldades acentuadas para padronização. Dessa forma, tem sido utilizado para detectar diferenças no vigor de lotes de sementes e para verificar o potencial de armazenamento de sementes de diversas hortaliças, como cenoura, cebola, alface e brássicas (Matthews, 1980; Powell \& Matthews, 1981; Powell \& Matthews, 1984a,b; Wang et al., 1994). Resultados consistentes com esse teste para a avaliação do vigor de sementes de hortaliças, no Brasil, foram obtidos por Panobianco \& Marcos Filho (1998), com pimentão; Rodo et al. (1998b) e Panobianco \& Marcos Filho (2001a), com tomate; e Sader et al. 
(2001), com brócolos. A literatura recomenda as seguintes combinações de grau de umidade/temperatura/período de exposição para a condução do teste:alface, couve-flor e couve de bruxelas, $20 \% / 45^{\circ} \mathrm{C} / 24 \mathrm{~h}$ (ISTA, 1995); berinjela, $24 \% / 41^{\circ} \mathrm{C} / 48 \mathrm{~h}$ (Bhéring et al., 2001b); beterraba e cenoura, $24 \% / 45^{\circ} \mathrm{C} / 24 \mathrm{~h}$ (ISTA, 1995); brócolos, $22 \% / 40^{\circ} \mathrm{C} / 24 \mathrm{~h}$ (Mendonça et al., 2000); ervilha, $20 \% / 45^{\circ} \mathrm{C} / 24 \mathrm{~h}$ (Bustamante et al., 1984; Powell et al., 1997; Larsen et al., 1998); maxixe, $19 \% / 45^{\circ} \mathrm{C} / 24 \mathrm{~h}$ (Torres et al., 1999); melancia, $24 \% / 41^{\circ} \mathrm{C} / 48 \mathrm{~h}$ (Bhéring et al., 2001a); melão, $21 \% / 45^{\circ} \mathrm{C} / 72 \mathrm{~h}$ (Oluoch \& Welbaum, 1996); nabo, $20 \% / 45^{\circ} \mathrm{C} / 24 \mathrm{~h}$ (Zhang \& Hampton, 1999); pepino, $24 \% / 45^{\circ} \mathrm{C} / 48 \mathrm{~h}$ (Bhéring et al., 2000); pimentão, $24 \% / 45^{\circ} \mathrm{C} / 24 \mathrm{~h}$ (Panobianco \& Marcos Filho, 1998); repolho, $24 \% / 45^{\circ} \mathrm{C} / 24 \mathrm{~h}$ (Strydom \& Van de Venter, 1998); tomate, 24\%/45 ${ }^{\circ} \mathrm{C} / 24 \mathrm{~h}$ (Alsadon et al., 1995; Panobianco \& Marcos Filho, 2001a).

Apesar do teste de deterioração controlada ser dirigido à avaliação do potencial fisiológico de sementes de hortaliças e estar sendo estudado para diversas espécies, não há informações a respeito desse teste para sementes de rabanete.

\subsubsection{Condutividade elétrica}

A organização das membranas celulares é máxima por ocasião da maturidade fisiológica (Abdul-Baki, 1980). Com a dessecação, estas sofrem processo de desorganização estrutural, estando tanto mais desorganizadas quanto menor for o grau de umidade da semente, perdendo, temporariamente, a sua integridade (Bewley \& Black, 1994). A integridade das membranas celulares, determinada pelo grau de alterações bioquímicas deteriorativas e/ou danos físicos, pode ser considerada como causa fundamental de diferenças no vigor de sementes (Powell, 1988).

O teste de condutividade elétrica avalia indiretamente o grau de estruturação das membranas celulares, através da determinação da quantidade 
de íons lixiviados em um a solução de embebição, inversamente relacionada à integridade das membranas celulares. As sementes são embebidas em determinado volume de água destilada, sob temperatura controlada, durante período pré-estabelecido. Em conseqüência da menor estruturação e seletividade das membranas, sementes de menor potencial fisiológico liberam maior quantidade de lixiviados; a avaliação é referente à concentração de íons na solução de embebição.

No início do processo de embebição, a capacidade da semente de reorganizar o sistema de membranas celulares e de reparar danos físicos e/ou biológicos que podem ter ocorrido durante o processo de produção, irá influenciar a quantidade e a natureza de lixiviados liberados para o meio externo (Simon \& Raja Harun, 1972; Bewley \& Black, 1994; e Vieira \& Krzyzanowski, 1999), entre os quais se encontram açúcares, aminoácidos, ácidos graxos, enzimas e íons inorgânicos, como $\mathrm{K}^{+}, \mathrm{Ca}^{++}, \mathrm{Mg}^{++}$e $\mathrm{Na}^{+}$(Short \& Lacy, 1976; Cortes \& Spaeth, 1994 e Taylor et al., 1995).

Considerando que os testes de vigor são mais sensíveis a variações de potencial fisiológico do que o teste de germinação (AOSA, 1983), qualquer evento que preceda a perda de poder germinativo pode servir como base para o desenvolvimento de testes de vigor. Porém, acredita-se que, quanto mais próximo da maturidade fisiológica ou mais distante da perda do poder germinativo estiver a variável avaliada, mais sensível será o teste. Nesse sentido, os testes que avaliam a integridade das membranas celulares seriam, teoricamente, os mais sensíveis para estimar o vigor (Marcos Filho, 1999a).

O teste de condutividade foi desenvolvido, inicialmente, para sementes de ervilha (Matthews \& Bradnock, 1967) e tem sido muito utilizado na avaliação do vigor de sementes dessa espécie, em várias partes do mundo (Hampton \& TeKrony, 1995). Em termos de padronização, é considerado um teste interessante e promissor.

Diversos fatores podem afetar os resultados da condutividade elétrica, dentre os quais destacam-se: genótipo dentro de uma mesma espécie ou 
cultivar (Short \& Lacy, 1976; Schmidt \& Tracy, 1989; Vieira et al., 1996; Panobianco e Vieira, 1996; Vieira et al., 1998; e Panobianco et al., 1999); estádio de desenvolvimento da semente (Powell, 1986); mudanças na estrutura e composição da semente durante o desenvolvimento (Styer \& Cantliffe, 1983); desestruturação das membranas (Givelberg et al., 1984; Powell, 1986); tamanho da semente (Tao, 1978; Loeffler, 1981; Deswal e Sheoran, 1993); massa da semente (Hepburn et al., 1984; Siddique \& Goodwin, 1985); temperatura de embebição (Leopold, 1980; Murphy \& Noland, 1982; Givelberg et al., 1984); período de embebição (Loeffler et al., 1988; Schmidt \& Tracy, 1989; Wang et al., 1994); volume de água utilizado (Tao, 1978; Loeffler et al., 1988; Hampton et al., 1994); teor de água inicial das sementes (Tao, 1978; McDonald \& Wilson, 1979; Loeffler et al., 1988; Hampton et al., 1992; Hampton et al., 1994; Carvalho, 1994; Penariol, 1997); presença de sementes danificadas fisicamente (Tao,1978); integridade do tegumento (Samad \& Pearce, 1978; Duke \& Kakefuda, 1981) e a sua permeabilidade (Powell \& Matthews, 1979); cor da semente (Short \& Lacy, 1976); tamanho do recipiente de embebição (Loeffler et al., 1988); qualidade da água (Tao, 1978; Loeffler et al., 1988); número de sementes constituintes da amostra avaliada (Hamppton et al., 1994); equipamento utilizado para a leitura da condutividade (Hepburn et al., 1984); e expressão dos resultados (Mullet \& Wilkinson, 1979; Siddique \& Goodwin, 1985).

Dentre os fatores mencionados, o período de embebição das sementes tem sido estudado com certa freqüência, visando agilizar a obtenção de informações sobre o vigor das sementes. A descrição inicial do teste de condutividade elétrica indica o período de 24 horas para a embebição das sementes; porém, devido à necessidade de obter respostas mais rápidas, têmsido efetuadas tentativas para reduzir esse período.

Estudos nesse sentido têm sido desenvolvidos para sementes de hortaliças, como a pesquisa conduzida por Andrade et al. (1995), que revelou resultados promissores para sementes de cenoura submetidas a períodos 
curtos de embebição, de trinta minutos e quatro horas, antes das leituras de condutividade elétrica. De acordo com Simon \& Mathavan (1986), a perda de solutos é mais intensa no início do processo de embebição, sendo que em sementes de cenoura, após 60 minutos de embebição, já ocorre estabilização do processo.

Em sementes de alface, Guimarães et al. (1993) constataram que o período de quatro horas de embebição foi o mais adequado para diferenciar lotes de alto e baixo vigor. Loomis \& Smith (1980), buscando a definição do protocolo do teste para avaliação do vigor de sementes de repolho, obtiveram as melhores respostas com quatro horas de embebição. Torres et al. (1998), visando a redução do período de condicionamento em sementes de maxixe, realizaram leituras após 2, 4, 8, 12, 16, 20 e 24 horas de embebição, concluindo que tal período pode ser reduzido para 4 horas. Resultados semelhantes foram obtidos por Dias et al. (1998), com quiabo, e por Krishnasamy \& Ramarajpalaniappan (1989), com tomate. Em trabalho realizado com sementes de tomate, Sá (1999) verificou a possibilidade de redução do tempo de embebição para 6 horas no teste de condutividade elétrica.

Outro fator de destaque é a temperatura de embebição, que reflete na velocidade de embebição e de lixiviação de eletrólitos do interior das células para o meio externo (Leopold, 1980). O efeito da temperatura afeta, basicamente, a quantidade e a velocidade de perda de lixiviados, traduzindo-se na magnitude do valor da condutividade, porém, sem alterar a classificação dos lotes (Hampton, 1995). Em sementes pequenas, a lixiviação máxima pode ocorrer num período inferior a 2 horas (Murphy \& Noland, 1982), enquanto em sementes maiores, como soja, verificou-se o aumento de lixiviação até 24-30 horas após o início da embebição, a $25^{\circ} \mathrm{C}$ (Loeffler et al., 1988).

A temperatura de avaliação também exerce efeito direto e significativo sobre os resultados da condutividade elétrica. Trabalhando com sementes de soja, Loeffler et al. (1988) verificaram que acréscimo ou redução de $5^{\circ} \mathrm{C}$ na temperatura de avaliação proporcionaram alterações significativas nos 
resultados da condutividade; recomendaram que o número de amostras retiradas da câmara $\left(25^{\circ} \mathrm{C}\right)$ deve ser suficiente para ser avaliado num espaço de, no máximo, 15 minutos.

Em relação ao número de sementes, Loeffler et al. (1988), trabalhando com sementes de soja, demonstraram que o uso de 50 sementes, em comparação a 25 , proporcionou redução do coeficiente de variação, levando a maior uniformidade dos resultados. Em estudo realizado com sementes de alface (25, 50 e 100 sementes), Guimarães et al. (1993) constataram que a utilização de 50 sementes foi mais adequada para a condução do teste para esta espécie. Em sementes de tomate, Sá (1999) não observou diferenças significativas em função do número de sementes empregado (25, 50 ou 100).

Outro fator que pode influir nos resultados de condutividade elétrica é o volume de água utilizado. Hampton et al. (1994) verificaram que o aumento na quantidade de água minimizou o feito do número de sementes, ou seja, quando trabalharam com volume maior de água $(250 \mathrm{~mL})$ a condutividade elétrica não sofreu interferência do número de sementes (50 e 100 sementes), enquanto que em menor quantidade de água $(125 \mathrm{~mL})$, variou significativamente em função do número de sementes empregado. A literatura apresenta diferentes volumes utilizados para condução do teste em diversas espécies, como: 100mL para pimentão (Demir \& Ellis, 1992); 75mL para alface (Guimarães et al., 1993), cebola (Torres, 1998), cenoura (Andrade et al., 1995) e tomate (Sá, 1999); $50 \mathrm{~mL}$ para cenoura (Rodo et al., 2000), pimentão (Trawatha et al., 1990) e tomate (Rodo et al., 1998a); 25mL para cebola (Piana et al., 1995), pimentão (Torres, 1996; Panobianco e Marcos Filho, 1998) e tomate (Cavariani et al., 1994).

A condutividade elétrica da solução de embebição de sementes tem sido utilizada para avaliar o vigor de sementes de várias espécies (Powell \& Matthews, 1981; Marcos Filho et al., 1987). Lima (1993) não verificou sensibilidade do teste para separação de lotes de alto e baixo vigor de sementes de cebola. Da mesma maneira, Argerich \& Bradford (1989) e 
Novembre et al. (1995) não obtiveram resultados satisfatórios com sementes de tomate. Trabalhando com sementes de pimentão, Torres (1996) observou que, dentre os testes de vigor avaliados, a condutividade elétrica não se relacionou à emergência das plântulas em campo. Entretanto, resultados consistentes para a avaliação do vigor de sementes de hortaliças foram obtidos por Guimarães et al. (1993), com alface; Mello et al. (1999), com brócolos; Piana et al. (1995), com cebola; Andrade et al. (1995), com cenoura; Dias et al. (1996), com couveflor, cebola e cenoura; Torres et al. (1998), com maxixe; Trawatha et al. (1990), Demir \& Ellis (1992), Dúran et al. (1997), Panobianco \& Marcos Filho (1998), Torres \& Minami (2000), com pimentão; Dias et al. (1998), com quiabo e feijãode-vagem; e Rodo et al (1998b) e Sá (1999).

Vários estudos a respeito do teste de condutividade elétrica para sementes como soja e ervilha, entre outras, estão disponíveis na literatura, porém, informações sobre metodologia específica para condução deste teste com sementes de rabanete não estão disponíveis.

\subsubsection{Lixiviação de potássio}

O teste de lixiviação de potássio, estudado com menor freqüência, é alternativa para avaliar o vigor de sementes. Este teste baseia-se no mesmo princípio do teste de condutividade elétrica, com a vantagem de proporcionar informações sobre o potencial fisiológico dos lotes, em período de tempo consideravelmente reduzido (Dias \& Marcos Filho, 1995).

O teste de condutividade elétrica avalia indiretamente a quantidade total de íons liberados durante a embebição de sementes. Uma porção significativa desses exsudados é constituída por íons inorgânicos; no entanto, poucos estudos têm sido realizados com a finalidade de identificar especificamente os cátions liberados para o meio externo durante o processo. Neste contexto, Samad \& Pearce (1978) verificaram a rápida liberação de $\mathrm{K}^{+}$e outros 
componentes durante os primeiros sessenta minutos de embebição de sementes de amendoim. Perdas de $\mathrm{Ca}^{++}, \mathrm{Mg}^{++}, \mathrm{Mn}^{++}, \mathrm{K}^{+}$e $\mathrm{Cl}^{-}$durante a embebição de sementes de repolho, envelhecidas artificialmente, foram observadas por Loomis \& Smith (1980), ao passo que outros trabalhos avaliaram as quantidades de $\mathrm{K}^{+}$e $\mathrm{Na}^{+}$liberados (McKersie \& Stinson, 1980). Estudos conduzidos com sementes de Solanum nigrum demonstraram que ocorrem perdas de $\mathrm{Ca}^{++}, \mathrm{Na}^{+}, \mathrm{Mg}^{++}$e $\mathrm{K}^{+}$durante a embebição (Givelberg et al., 1984). Oliveira (1990) quantificou a presença de $\mathrm{Ca}^{++}, \mathrm{Na}^{+}, \mathrm{Mg}^{++}$e $\mathrm{K}^{+}$no exsudado de sementes de soja, após 90 minutos de embebição, a $28^{\circ} \mathrm{C}$, e observou relação significativa entre a perda de germinação e a liberação de íons, com exceção do $\mathrm{Na}^{+}$.

O potássio tem recebido maior destaque por se tratar do principal íon lixiviado pelas sementes (Lott et al., 1991). Mullett \& Considine (1980) demonstraram, em sementes de ervilha e de feijão, que 25 a $50 \%$ do total de eletrólitos liberados correspondeu ao íon $\mathrm{K}+$, o mesmo ocorrendo para sementes de algodão (Woodstock et al., 1985). Granqvist (1987), em sementes de cenoura, mostrou que as perdas de potássio e de cálcio foram semelhantes, mas superiores às de sódio e magnésio.

A quantidade de potássio lixiviada em sementes embebidas tem sido utilizada como um indicador da integridade do sistema de membranas celulares (Halloin, 1975; McKersie \& Stinson, 1980; Woodstock et al., 1985). Simon \& Raja-Harun (1972) verificaram estrita relação entre os resultados de condutividade elétrica e quantidade de potássio liberado após 24 horas de embebição, em sementes de ervilha. Em sementes de algodão, a concentração de íons potássio liberados após 60 minutos de embebição correspondeu à condutividade elétrica avaliada com 15 e 45 minutos (Halloin, 1975). Em estudo conduzido com sementes de feijão, Moss \& Mullet (1982) utilizaram a quantidade de potássio lixiviado após 72 horas de embebição como parâmetro indicativo de vigor. Trabalhando com sementes de soja, Marcos Filho et al. (1982) verificaram que a lixiviação de potássio decresceu proporcionalmente à 
elevação do poder germinativo e vigor das sementes, durante o processo de maturação. Com o desenvolvimento da metodologia, Custódio \& Marcos Filho (1997) verificaram diferenças de vigor em sementes de soja após 30 minutos de embebição, destacando ainda vantagens como simplicidade, precisão e rapidez, em comparação com o teste de condutividade elétrica.

Panobianco \& Marcos Filho (2001b), trabalhando com sementes de tomate; Miguel (2001), com milho; e Custódio \& Marcos Filho (1997), com soja mostraram que a liberação de $\mathrm{K}$ está diretamente ligada ao estado das membranas e independe da quantidade de $\mathrm{K}$ nas sementes.

Em relação às hortaliças, espécies como aipo, alface e cenoura apresentaram $90 \%$ da lixiviação de potássio num período de 5 a 15 minutos (Simon \& Mathavan, 1986). Entretanto, essas observações não foram realizadas em pesquisa dirigida ao estudo da lixiviação de potássio como um teste de vigor.

Resultados consistentes sobre a utilização do teste de lixiviação de potássio para a avaliação do vigor de sementes de hortaliças foram obtidos por Dias et al. (1998), com quiabo e feijão-de-vagem; Panobianco \& Marcos Filho (2001b), com tomate; e Rodo \& Marcos Filho (2001b), com cebola, permitindo a identificação de lotes de qualidade inferior com significativa rapidez. Considerando que pesquisas voltadas à utilização do teste de lixiviação de potássio para avaliação do potencial fisiológico de sementes de hortaliças são escassas, são necessários estudos adicionais para adequação e padronização de metodologia, visando ampliar sua utilização.

\subsubsection{Considerações gerais}

Diante do exposto, verifica-se, de um modo geral, que o estudo de testes de vigor para avaliação do potencial fisiológico de sementes de hortaliças ainda é pequeno, quando comparado com outras culturas de interesse econômico. Entretanto, vários pesquisadores estão se dedicando ao estudo do vigor em 
sementes dessas espécies utilizando os testes disponíveis, visando estabelecer procedimentos específicos e obter a padronização, com ênfase a testes com capacidade de proporcionar resultados rápidos, precisos e aplicáveis em programas de controle de qualidade. 


\section{MATERIAL E MÉTODOS}

O presente trabalho foi conduzido no Laboratório de Sementes do Departamento de Produção Vegetal da Escola Superior de Agricultura "Luiz de Queiroz", Universidade de São Paulo, em Piracicaba-SP, utilizando-se sementes de três cultivares de rabanete (Raphanus sativus L.), no período de janeiro a julho de 2003. Foram determinados o grau de umidade e a germinação das sementes, a emergência de plântulas e estudados procedimentos para a condução dos testes de envelhecimento acelerado, deterioração controlada, condutividade elétrica e lixiviação de potássio. Os testes de germinação e primeira contagem de germinação foram realizados três vezes, com intervalos de aproximadamente 30 dias entre as avaliações.

\subsection{Sementes}

Foram utilizados os cultivares Gigante Siculo (4 lotes), Cometa (3 lotes) e Saxa (2 lotes), sendo as sementes dos cultivares Gigante Siculo e Saxa, importadas da Itália; e do cultivar Cometa, importadas dos Estados Unidos da América.

As sementes recebidas estavam embaladas em recipientes herméticos (latas) e; após a homogeneização realizada com auxílio de divisor de solos, foram acondicionadas em sacos de papel. Durante o período experimental, as sementes permaneceram armazenadas em câmara a $20^{\circ} \mathrm{C}$ e $50 \%$ de umidade relativa do ar (U.R.). 


\subsection{Determinação do grau de umidade}

A determinação do grau de umidade foi realizada pelo método da estufa a $105 \pm 3^{\circ} \mathrm{C}$, durante 24 horas, de acordo com as Regras para Análise de Sementes - RAS (Brasil, 1992), utilizando-se duas amostras com aproximadamente $2,0 \mathrm{~g}$ de sementes para cada lote. Os resultados foram expressos em percentagem média (base úmida) por lote.

\subsection{Teste de germinação}

Utilizaram-se quatro repetições de 50 sementes por lote, cada uma distribuída sobre duas folhas de papel mata-borrão, previamente umedecidas com quantidade de água equivalente a 2,5 vezes o peso do substrato (Menezes et al., 1993), colocadas no interior de caixas plásticas transparentes $(11,5 \times 11,5 \times 3,5 \mathrm{~cm})$. Em seguida, estas foram mantidas em germinador sob alternância $20-30^{\circ} \mathrm{C}$. As avaliações foram efetuadas de acordo com as Regras para Análise de Sementes (Brasil, 1992), aos quatro e dez dias após a semeadura, sendo os resultados expressos em percentagem média de plântulas normais para cada lote. 


\subsection{Primeira contagem de germinação}

Esses dados foram obtidos computando-se a percentagem de plântulas normais obtidas aos quatro dias após a instalação do teste de germinação. Os resultados foram expressos em percentagem média de plântulas normais para cada lote.

\subsection{Envelhecimento acelerado (procedimento tradicional)}

O teste foi conduzido utilizando-se caixas plásticas transparentes $(11,5 \times 11,5 \times 3,5 \mathrm{~cm})$ como compartimentos individuais (mini-câmaras), possuindo em seu interior suportes para apoio de uma tela metálica. Na superfície de cada uma destas foram distribuídas, em camada única, cerca de 4,0g de sementes de cada lote. Para o controle da umidade relativa do ar no interior das caixas, foram colocados $40 \mathrm{~mL}$ de água. As caixas tampadas foram mantidas em câmara do tipo "jaquetada de água" (modelo 3015 VWR Scientific) regulada a $41^{\circ} \mathrm{C}$ ou a $45^{\circ} \mathrm{C}$, durante 48,72 ou 96 horas.

Decorrido cada período de envelhecimento, quatro subamostras de 50 sementes por tratamento foram colocadas para germinar, seguindo o mesmo procedimento utilizado para o teste de germinação. A avaliação foi realizada aos quatro dias após a semeadura, computando-se a percentagem de plântulas normais. Foi determinado também, o teor de água das sementes antes e após cada período de envelhecimento, visando à avaliação da uniformidade das condições do teste. 


\subsection{Envelhecimento acelerado (solução saturada de $\mathrm{NaCl}$ )}

Esta avaliação foi conduzida da mesma maneira relatada para procedimento tradicional (item 3.5) adicionando-se, porém, $40 \mathrm{~mL}$ de solução saturada de $\mathrm{NaCl}$ ao fundo de cada caixa plástica, em substituição à água, proporcionando ambiente com 76\% UR (Jianhua \& McDonald, 1996).

\subsection{Deterioração controlada}

O grau de umidade das sementes foi ajustado artificialmente para três níveis diferentes, $20 \%, 22 \%$ e $24 \%$, através do método da atmosfera úmida (Rossetto et al., 1995). Para tanto, foram colocados $40 \mathrm{~mL}$ de água em caixas plásticas transparentes $(11,5 \times 11,5 \times 3,5 \mathrm{~cm})$ com suportes para apoio de uma tela metálica e, sobre esta, distribuídas amostras de aproximadamente $6,5 \mathrm{~g}$ de sementes, em camada uniforme. As caixas foram tampadas e mantidas em germinador a $20^{\circ} \mathrm{C}$. Durante o umedecimento artificial, o grau de umidade de cada amostra foi monitorado mediante pesagens sucessivas, até se obterem os valores desejados.

Uma vez obtidos os graus de umidade planejados, cada amostra foi colocada em embalagem laminada de alumínio + plástico, fechada hermeticamente e mantida por cinco dias em câmara fria $\left(8-10^{\circ} \mathrm{C}\right)$, com a finalidade de assegurar distribuição uniforme da água no interior das sementes. Em seguida, as amostras foram mantidas em banho-maria a $45^{\circ} \mathrm{C}$, durante 24 horas. Posteriormente, foram imersas rapidamente em água fria para reduzir a temperatura, sendo instalado em seguida o teste de germinação (Powell, 1995). A avaliação foi efetuada aos quatro dias após a semeadura, computando-se a percentagem média de plântulas normais para cada lote. Foi determinado, também, o grau de umidade das sementes após esse de envelhecimento 
artificial, segundo os critérios estabelecidos na Regras para Análise de Sementes (Brasil, 1992).

\subsection{Condutividade elétrica}

Para determinar a marcha de liberação de eletrólitos para cada lote, foram estudados os efeitos do período de embebição, do volume de água destilada e do número de sementes, utilizando-se 25 e 50 sementes colocadas em copos plásticos contendo 25,50 ou $75 \mathrm{~mL}$ de água destilada e mantidas a $25^{\circ} \mathrm{C}$ durante $1,2,4,6,8,16$ e 24 horas. Essas avaliações foram conduzidas com quatro repetições, utilizando-se sementes previamente pesadas (precisão de $0,0001 \mathrm{~g}$ ), embebidas em água destilada e mantidas em germinador durante cada período considerado. A quantidade de lixiviados foi determinada com o auxílio de condutivímetro marca DIGIMED, modelo DM-31, e os resultados, expressos em $\mu \mathrm{S} . \mathrm{cm}^{-1} \cdot \mathrm{g}^{-1}$ de semente. A análise estatística dos dados considerou apenas os períodos de 1, 2, 4 e 6 horas de embebição.

\subsection{Lixiviação de potássio}

A lixiviação de potássio da solução de embebição das sementes foi avaliada estudando-se os efeitos dos volumes de água de 25,50 e $75 \mathrm{~mL}$, do número de sementes por amostra (50 e 100) e dos períodos de embebição de $30,60,90,120,150$ e 180 minutos, a $25^{\circ} \mathrm{C}$. O teste foi conduzido utilizando-se quatro repetições com sementes previamente pesadas (precisão de 0,0001g), colocadas em copos plásticos contendo água destilada, mantidos em germinador durante cada período previsto para a embebição. As leituras foram efetuadas em fotômetro de chama DIGIMED NK-2020, utilizando-se o padrão 
de 50 ppm de potássio ajustado para leitura 50; os resultados foram expressos em $\mathrm{ppm} \mathrm{K/g}$ de semente.

Inicialmente, foi estabelecida a curva de calibração do fotômetro de chama, para a verificação da linearidade da curva da solução padrão de 50 ppm de potássio ajustada para leitura 50 . Esta calibração foi estabelecida através de regressão linear e avaliada com seis observações, sendo uma com água destilada, ajustada para leitura zero e, as demais, realizadas com soluções padrão com concentração conhecida de potássio $(5,10,20,30$ e 40 ppm, ajustados para leitura 5, 10, 20, 30 e 40, respectivamente), para verificar a linearidade da curva (Custódio \& Marcos Filho,1997). O padrão estudado apresentou linearidade com alto coeficiente de determinação $\left(R^{2}=0,9906\right)$, confirmando a adequação da curva para determinação do potássio lixiviado pelas sementes.

Os padrões foram obtidos partindo-se, inicialmente, de uma solução de 1000 ppm de K. Através da fórmula C.V = C1.V1, onde C é a concentração da solução e $V$ é o volume da solução, foram obtidos os padrões necessários para proceder à calibração do aparelho.

Para o cálculo da lixiviação de potássio efetuou-se a multiplicação da leitura obtida no fotômetro de chama ( $\mathrm{ppm} \mathrm{K/mL)}$ pelo volume de água destilada $(\mathrm{mL})$ e pelo coeficiente de correção obtido na regressão linear, sendo o resultado dessa multiplicação dividido pelo peso da amostra $(\mathrm{g})$. O resultado final foi expresso em ppm de $\mathrm{K} / \mathrm{g}$ de semente.

As leituras das quantidades de potássio lixiviado pelas sementes de rabanete, nos diferentes períodos de embebição, foram feitas utilizando o mesmo material; em função disto, na execução dos cálculos, descontou-se $1 \mathrm{~mL}$ de solução, após cada leitura, porque o fotômetro de chama utiliza $1 \mathrm{~mL}$ de solução para determinar a quantidade de potássio lixiviado, segundo as informações técnicas do aparelho. 


\subsection{Emergência de plântulas}

Para a realização do teste de emergência de plântulas foram utilizadas bandejas de poliestireno ("isopor") com células individuais, contendo substrato comercial (tipo Plantmax), mantidas em condições de ambiente, com irrigação periódica. Para cada lote, foram utilizadas quatro repetições de 50 sementes, colocando-se uma semente por célula. A avaliação da emergência das plântulas foi efetuada 10 dias após a semeadura, mediante a contagem de plântulas normais emergidas, avaliadas de acordo com os critérios adotados para avaliação da parte aérea de plântulas normais em um teste de germinação. Os resultados foram expressos em percentagem média de plântulas normais para cada lote.

\subsection{Procedimento estatístico}

Os dados em percentagem, provenientes dos testes de germinação, primeira contagem de germinação, envelhecimento acelerado, deterioração controlada e emergência de plântulas foram transformados em arc sen $\sqrt{ } \mathrm{x} / 100$. Os dados referentes aos testes de condutividade elétrica e de lixiviação de potássio não sofreram transformação.

Os dados obtidos nos testes de germinação e de primeira contagem de germinação foram analisados utilizando-se delineamento inteiramente casualizado em arranjo fatorial (lotes $\mathrm{x}$ avaliações), com quatro repetições, considerando primeira, segunda e terceira avaliações ${ }_{2}$ segundo o esquema apresentado na Tabela 1. 
Tabela 1. Esquema de análise de variância dos dados obtidos nos testes de germinação e de primeira contagem de germinação para as sementes de cada cultivar

\begin{tabular}{|c|c|c|c|}
\hline \multirow{3}{*}{ Causas de variação } & \multicolumn{3}{|c|}{ Graus de Liberdade } \\
\hline & \multicolumn{3}{|c|}{ Cultivares } \\
\hline & Gigante Siculo & Cometa & Saxa \\
\hline Lotes & 3 & 2 & 1 \\
\hline Avaliações & 2 & 2 & 2 \\
\hline Lotes x Avaliações & 6 & 4 & 2 \\
\hline Resíduo & 36 & 27 & 18 \\
\hline Total & 47 & 35 & 23 \\
\hline
\end{tabular}

Os dados obtidos nos testes de envelhecimento acelerado (procedimento tradicional e com solução saturada de $\mathrm{NaCl}$ ) e de deterioração controlada foram analisados conforme delineamento inteiramente casualizado em arranjo fatorial (lotes x períodos ou grau de umidade - GU), com quatro repetições, segundo o esquema apresentado na Tabela 2.

Tabela 2. Esquema de análise de variância dos dados referentes aos testes de envelhecimento acelerado e deterioração controlada para as sementes de cada cultivar e temperatura

\begin{tabular}{|c|c|c|c|}
\hline \multirow{3}{*}{ Causas de variação } & \multicolumn{3}{|c|}{ Graus de Liberdade } \\
\hline & \multicolumn{3}{|c|}{ Cultivares } \\
\hline & Gigante Siculo & Cometa & Saxa \\
\hline Lotes & 3 & 2 & 1 \\
\hline Períodos ou GU & 2 & 2 & 2 \\
\hline Lotes x Períodos ou GU & 6 & 4 & 2 \\
\hline Resíduo & 36 & 27 & 18 \\
\hline Total & 47 & 35 & 23 \\
\hline
\end{tabular}


Os dados obtidos no teste de condutividade elétrica foram analisados utilizando-se delineamento inteiramente casualizado em arranjo fatorial (lotes $\mathrm{x}$ períodos), com quatro repetições, segundo o esquema apresentado na Tabela 3.

Tabela 3. Esquema de análise de variância dos dados do teste de condutividade elétrica para as sementes de cada cultivar

\begin{tabular}{|c|c|c|c|}
\hline \multirow{3}{*}{ Causas de variação } & \multicolumn{3}{|c|}{ Graus de Liberdade } \\
\hline & \multicolumn{3}{|c|}{ Cultivares } \\
\hline & Gigante Siculo & Cometa & Saxa \\
\hline Lotes & 3 & 2 & 1 \\
\hline Períodos & 3 & 3 & 3 \\
\hline Lotes x Períodos & 9 & 6 & 3 \\
\hline Resíduo & 48 & 36 & 24 \\
\hline Total & 63 & 47 & 31 \\
\hline
\end{tabular}

Os dados obtidos no teste de lixiviação de potássio foram analisados utilizando-se delineamento inteiramente casualizado em arranjo fatorial (lotes $\mathrm{x}$ períodos), com quatro repetições, segundo o esquema apresentado na Tabela 4. 
Tabela 4. Esquema de análise de variância dos dados teste de lixiviação de potássio para as sementes de cada cultivar

\begin{tabular}{|c|c|c|c|}
\hline \multirow{3}{*}{ Causas de variação } & \multicolumn{3}{|c|}{ Graus de Liberdade } \\
\hline & \multicolumn{3}{|c|}{ Cultivares } \\
\hline & Gigante Siculo & Cometa & Saxa \\
\hline Lotes & 3 & 2 & 1 \\
\hline Períodos & 5 & 5 & 5 \\
\hline Lotes $x$ Períodos & 15 & 10 & 5 \\
\hline Resíduo & 72 & 54 & 36 \\
\hline Total & 95 & 71 & 47 \\
\hline
\end{tabular}

Os dados resultantes do teste de emergência de plântulas foram analisados para o cultivar Gigante Siculo utilizando-se delineamento inteiramente casualizado, com quatro repetições, conforme o esquema apresentado na Tabela 5. Para os demais cultivares, a análise de variância não foi realizada devido ao número insuficiente de variáveis.

Tabela 5. Esquema de análise de variância dos dados obtidos no teste de emergência de plântulas para as sementes do cultivar Gigante Siculo

\begin{tabular}{lc}
\hline Causas de variação & Graus de Liberdade \\
\hline Lotes & 3 \\
Resíduo & 12 \\
Total & 15 \\
\hline
\end{tabular}

A comparação de médias foi realizada pelo teste de Tukey $(p \leq 0,05)$. Os dados referentes ao grau de umidade das sementes não foram submetidos à análise estatística. A análise estatística foi realizada através do Sistema de Análise Estatística - SANEST (Zonta et al., 1984). 


\section{RESULTADOS E DISCUSSÃO}

\subsection{Caracterização inicial dos lotes de sementes de rabanete}

As diferenças no potencial fisiológico inicial dos lotes de sementes de rabanete podem ser observadas pelos resultados dos testes de germinação, e de emergência de plântulas; determinou-se também o grau de umidade das sementes (Tabela 6). Os valores médios de germinação mostram que todos os lotes em análise possuíam germinação superior à estabelecida ( $\geq 80 \%$ ) nos padrões para a comercialização de sementes de rabanete (CATI, 1999).

Os valores de germinação, assim como da primeira contagem e de emergência de plântulas, não permitiram diferenciar os lotes do cultivar Gigante Siculo, cujas médias variaram de 91 a 93\% (Tabela 6). Resultados elevados de germinação entretanto não significam necessariamente que os lotes possuem alto vigor, uma vez que o teste de germinação é conduzido em condições favoráveis de temperatura, umidade e luminosidade, permitindo ao lote expressar o potencial máximo para produzir plântulas normais (Marcos Filho, 1999a). Inclusive, Hampton \& Tekrony (1995) observaram que a maior limitação do teste de germinação é sua inabilidade para detectar diferenças de potencial fisiológico entre lotes com alta germinação, indicando a necessidade de complementar essa informação.

Para os cultivares Cometa e Saxa, houve diferença significativa tanto na primeira contagem como na, percentagem final de germinação, com destaque para os lotes 7 de 'Cometa' e 9 de 'Saxa'. Observa-se que mesmo os lotes com 
menor percentagem de germinação (5 e 8), estavam situados na Fase 1 da curva de perda de viabilidade (Powell, 1986), ou seja, acima de 80\%. A interação lotes $x$. avaliações não foi significativa, de modo que os resultados apresentados na Tabela 6 representam médias das três avaliações realizadas.

Tabela 6. Dados médios (\%) obtidos em testes de germinação (TG), primeira contagem de germinação (PCG), emergência de plântulas (EP) e determinação do grau de umidade (GU) para lotes de sementes dos cultivares Gigante Siculo, Cometa e Saxa (médias de três avaliações)

\begin{tabular}{|c|c|c|c|c|c|}
\hline Cultivares & Lotes & TG (\%) & PCG (\%) & EP (\%) & GU (\%) \\
\hline & 1 & $92 a^{*}$ & $92 a$ & $98 a$ & 5,7 \\
\hline Gigante & 2 & $91 a$ & $91 a$ & $99 a$ & 5,8 \\
\hline \multirow[t]{2}{*}{ Siculo } & 3 & $91 a$ & $91 a$ & $94 a$ & 5,8 \\
\hline & 4 & $94 a$ & $93 a$ & $93 a$ & 5,9 \\
\hline \multirow[t]{2}{*}{ C.V. (\%) } & & 5,52 & 4,90 & 5,56 & \\
\hline & 5 & $89 b$ & $88 b$ & 92 & 5,7 \\
\hline \multirow[t]{2}{*}{ Cometa } & 6 & $92 a b$ & $92 a b$ & 98 & 5,9 \\
\hline & 7 & $95 a$ & $94 a$ & 99 & 5,9 \\
\hline C.V. (\%) & & 6,25 & 5,69 & & \\
\hline \multirow[t]{2}{*}{ Saxa } & 8 & $85 b$ & $84 b$ & 98 & 6,2 \\
\hline & 9 & $89 a$ & $89 a$ & 97 & 6,0 \\
\hline C.V. (\%) & & 5,38 & 5,61 & & \\
\hline
\end{tabular}

${ }^{*}$ Comparação de médias dentro de cada coluna pelo teste de Tukey $(p \leq 0,05)$.

A percentagem de emergência de plântulas foi semelhante entre os lotes dos cultivares Cometa e Saxa (Tabela 6). Porém, a análise de variância não foi realizada devido ao número insuficiente de variáveis. Os lotes 6 e 7 do cultivar Cometa apresentaram média numericamente superior à do lote 5 . A emergência de plântulas também foi semelhante entre os lotes do cultivar Saxa. 
Para os três cultivares, a porcentagem média de emergência variou entre $92 \mathrm{e}$ 99\%, mostrando-se satisfatória; esse teste foi conduzido sob condições favoráveis de ambiente, não detectando diferenças de potencial fisiológico entre os lotes.

O teor de água das sementes (Tabela 6) dos diferentes lotes, dentro de cada cultivar, não apresentou variação elevada, o que é importante, pois a uniformidade do teor de água das sementes é essencial para a padronização das avaliações e obtenção de resultados consistentes (Marcos Filho et al., 1987; Loeffler et al., 1988; Krzyzanowski et al., 1991; Marcos Filho,1999a).

\subsection{Envelhecimento acelerado (procedimento tradicional)}

Os resultados referentes ao teste de envelhecimento acelerado tradicional, utilizando-se duas temperaturas e três períodos de envelhecimento, são apresentados na Tabela 7. A interação lotes $x$. períodos de exposição foi significativa, demonstrando existir influência dos períodos de exposição à temperatura e umidade relativa elevadas sobre o desempenho das sementes nesse teste.

Verificou-se que, para o cultivar Gigante Siculo, o envelhecimento acelerado tradicional foi eficiente em separar lotes, sendo o lote 4 identificado como superior e o lote 1 como inferior, quando o teste foi conduzido a $41^{\circ} \mathrm{C}$, durante 48 e 72 horas. Também, para os cultivares Cometa e Saxa, o período de 48 horas de exposição a $41^{\circ} \mathrm{C}$ foi satisfatório para diferenciar lotes. Outros autores, trabalhando com esta mesma combinação, obtiveram sucesso na separação de lotes de berinjela (Bhéring et al., 2001b), de cenoura (Rodo et al., 2000), de maxixe (Silva et al., 1998) e de melancia (Bhéring et al., 2001a). 
Tabela 7. Dados médios (\%) obtidos em testes de envelhecimento acelerado tradicional de lotes de sementes dos cultivares Gigante Siculo, Cometa e Saxa, em três períodos, a $41^{\circ} \mathrm{C}$ e $45^{\circ} \mathrm{C}$

\begin{tabular}{|c|c|c|c|c|c|c|c|}
\hline \multirow{2}{*}{ Cultivares } & \multirow{2}{*}{ Lotes } & \multicolumn{3}{|c|}{$41^{\circ} \mathrm{C}$} & \multicolumn{3}{|c|}{$45^{\circ} \mathrm{C}$} \\
\hline & & $48 h$ & $72 \mathrm{~h}$ & $96 h$ & $48 h$ & $72 \mathrm{~h}$ & $96 \mathrm{~h}$ \\
\hline & 1 & 82Ba* & $82 \mathrm{Ba}$ & $88 \mathrm{ABa}$ & $58 \mathrm{Cb}$ & $77 \mathrm{Ba}$ & $47 \mathrm{Bb}$ \\
\hline Gigante & 2 & $84 \mathrm{ABa}$ & 88Aba & $82 \mathrm{Ba}$ & $78 \mathrm{Bb}$ & 91Aa & $70 A b$ \\
\hline Siculo & 3 & 87ABa & 88Aba & $87 \mathrm{Ba}$ & $86 \mathrm{Abb}$ & 94Aa & $76 \mathrm{Ab}$ \\
\hline & 4 & 93Aa & 91Aa & 96Aa & 89Aa & 91Aa & $76 \mathrm{Ab}$ \\
\hline C.V. (\%) & & 7,09 & & & 7,01 & & \\
\hline & 5 & $76 \mathrm{Bb}$ & 87Aa & $82 A a b$ & 79Ba & $84 \mathrm{Ba}$ & $44 \mathrm{Bb}$ \\
\hline & 6 & $92 \mathrm{Aa}$ & $78 A b$ & $85 A a b$ & 93Aa & 94Aa & $71 \mathrm{Ab}$ \\
\hline Cuncla & 7 & 90Aa & 87Aa & $88 \mathrm{Aa}$ & $84 \mathrm{Ba}$ & $81 \mathrm{Ba}$ & $50 \mathrm{Bb}$ \\
\hline C.V. (\%) & & 6,89 & & & 7,65 & & \\
\hline Caya & 8 & $72 A b$ & 89Aa & $88 \mathrm{Aa}$ & $75 \mathrm{Ab}$ & 87Aa & $19 B c$ \\
\hline & 9 & $63 \mathrm{Bb}$ & $83 \mathrm{Ba}$ & $81 \mathrm{Ba}$ & $54 \mathrm{Ba}$ & $51 \mathrm{Ba}$ & $50 A a$ \\
\hline C.V. (\%) & & 4,91 & & & 9,56 & & \\
\hline
\end{tabular}

*Letras maiúsculas: comparação de médias dentro de cada coluna pelo teste de Tukey $(p \leq 0,05)$. Letras minúsculas: comparação de médias dentro de cada linha pelo teste de Tukey $(p \leq 0,05)$.

Os diferentes períodos de exposição das sementes ao teste de envelhecimento acelerado a $45^{\circ} \mathrm{C}$ não apresentaram resultados consistentes para os lotes dos cultivares estudados. Uma observação que poderia ser destacada é a redução drástica da percentagem de germinação nos casos em que o teor de água das sementes excedeu $40 \%$ após o envelhecimento acelerado (Tabela 8), ou seja, a associação entre temperatura elevada $\left(45^{\circ} \mathrm{C}\right) \mathrm{e}$ alta umidade relativa do ar promove degradação acentuada no metabolismo 
das sementes. Deve-se acrescentar ainda o fato dos tratamentos realizados nessa temperatura sofrerem aumento da incidência de patógenos.

Os dados referentes ao grau de umidade das sementes após a realização dos testes com procedimento tradicional são apresentados na Tabela 8.

Tabela 8. Dados médios (\%) de grau de umidade de lotes de sementes dos cultivares Gigante Siculo, Cometa e Saxa, obtidos em testes de envelhecimento acelerado tradicional, obtidos após a exposição a três períodos, a $41^{\circ} \mathrm{C}$ e $45^{\circ} \mathrm{C}$

\begin{tabular}{|c|c|c|c|c|c|c|c|}
\hline \multirow{2}{*}{ Cultivares } & \multirow{2}{*}{ Lotes } & \multicolumn{3}{|c|}{$41^{\circ} \mathrm{C}$} & \multicolumn{3}{|c|}{$45^{\circ} \mathrm{C}$} \\
\hline & & $48 h$ & $72 \mathrm{~h}$ & $96 h$ & $48 h$ & $72 h$ & $96 h$ \\
\hline & 1 & 36,0 & 37,0 & 38,3 & 33,2 & 37,2 & 38,1 \\
\hline Gigante & 2 & 35,7 & 37,9 & 37,2 & 34,5 & 36,9 & 36,6 \\
\hline \multirow[t]{3}{*}{ Siculo } & 3 & 35,3 & 37,7 & 37,4 & 34,5 & 36,5 & 37,7 \\
\hline & 4 & 36,1 & 38,6 & 39,2 & 36,2 & 38,2 & 39,4 \\
\hline & 5 & 33,9 & 36,9 & 38,1 & 35,3 & 35,8 & 38,4 \\
\hline \multirow[t]{2}{*}{ Cometa } & 6 & 35,2 & 36,5 & 38,1 & 34,9 & 36,7 & 37,5 \\
\hline & 7 & 36,5 & 38,8 & 39,4 & 37,2 & 38,7 & 40,2 \\
\hline \multirow{2}{*}{ Saxa } & 8 & 38,2 & 38,5 & 40,1 & 37,7 & 39,6 & 40,4 \\
\hline & 9 & 37,8 & 38,7 & 40,0 & 37,0 & 38,6 & 40,1 \\
\hline
\end{tabular}

A comparação de amostras que apresentem graus de umidade semelhantes antes do envelhecimento acelerado é conveniente, embora diferenças de até $2 \%$ não sejam comprometedoras (Marcos Filho, 1999a). No presente estudo, o grau de umidade inicial das sementes antes do envelhecimento acelerado foi semelhante entre os lotes, variando de $5,7 \%$ a 6,2\% (Tabela 6). 
Um dos principais indicadores da uniformidade das condições do envelhecimento acelerado é o grau de umidade das sementes após o teste, pois variações de 3 a 4 pontos percentuais entre amostras são consideradas toleráveis (Tomes et al., 1998; Marcos Filho, 1999a). O grau de umidade das sementes após os períodos de envelhecimento (Tabela 8) variou entre lotes do mesmo cultivar de 0,1 a 2,9 pontos percentuais para o envelhecimento acelerado tradicional, estando estas variações inferiores aos limites toleráveis.

\subsection{Envelhecimento acelerado (solução saturada de $\mathrm{NaCl}$ )}

$\mathrm{Na}$ Tabela 9 podem ser observados os resultados referentes ao teste de envelhecimento acelerado com solução saturada de $\mathrm{NaCl}$, utilizando-se duas temperaturas e três períodos de envelhecimento. Verificou-se, para o cultivar Gigante Siculo, que os testes de envelhecimento acelerado com solução saturada de $\mathrm{NaCl}$ não detectaram diferenças no potencial fisiológico entre os lotes estudados. Nota-se que os valores de germinação observados foram elevados, confirmando o alto vigor desses lotes. Talvez, o teor de água máximo de $10 \%$, atingido pelas sementes nesse teste, mesmo associado a temperaturas elevadas, não tenha sido suficiente para promover estresses, que resultem na diminuição do desempenho germinativo. Ribeiro \& Carvalho (2001), trabalhando com sementes de cenoura, alface e brócolos, também observaram que o controle da umidade relativa do ar no interior dos compartimentos (gerbox), mediante o uso de soluções saturadas de $\mathrm{NaCl}$ e $\mathrm{KCl}$ não foi eficiente para a avaliação do vigor. 
Tabela 9. Dados médios (\%) obtidos em testes de envelhecimento acelerado com solução saturada de $\mathrm{NaCl}$ de lotes de sementes dos cultivares Gigante Siculo, Cometa e Saxa, em três períodos a $41^{\circ} \mathrm{C}$ e $45^{\circ} \mathrm{C}$

\begin{tabular}{|c|c|c|c|c|c|c|c|}
\hline \multirow{2}{*}{ Cultivares } & \multirow{2}{*}{ Lotes } & \multicolumn{3}{|c|}{$41^{\circ} \mathrm{C}$} & \multicolumn{3}{|c|}{$45^{\circ} \mathrm{C}$} \\
\hline & & $48 h$ & $72 h$ & $96 h$ & $48 h$ & $72 h$ & $96 h$ \\
\hline & 1 & $84 \mathrm{Aa}^{*}$ & 86Aa & 90Aa & 84Aa & 87Aa & 82Aa \\
\hline Gigante & 2 & $85 \mathrm{Aa}$ & 89Aa & $82 \mathrm{Aa}$ & 87Aa & $85 A a$ & 89Aa \\
\hline Siculo & 3 & 89Aa & 84Aa & 90Aa & 90Aa & 88Aa & 88Aa \\
\hline & 4 & $91 \mathrm{Aa}$ & 93Aa & 90Aa & 83Aa & 91Aa & 91Aa \\
\hline C.V. (\%) & & 6,74 & & & 6,54 & & \\
\hline & 5 & $80 \mathrm{ABa}$ & 87Aa & 85Aa & 87Aa & 83Ba & $81 \mathrm{Ba}$ \\
\hline Comoto & 6 & $78 \mathrm{Bb}$ & 88Aa & $92 \mathrm{Aa}$ & 90Aa & 87ABa & 90Aa \\
\hline Cuncta & 7 & 88Aa & 89Aa & 88Aa & $70 \mathrm{Bb}$ & $92 \mathrm{Aa}$ & 77Bb \\
\hline C.V. (\%) & & 6,08 & & & 5,80 & & \\
\hline Cayn & 8 & $68 A b$ & $72 A b$ & 81Aa & $69 A b$ & 88Aa & $66 \mathrm{Bb}$ \\
\hline שand & 9 & $66 A b$ & 75Aab & 77Aa & $74 A b$ & 87Aa & $79 A b$ \\
\hline C.V. (\%) & & 5,40 & & & 5,05 & & \\
\hline
\end{tabular}

*Letras maiúsculas: comparação de médias dentro de cada coluna pelo teste de Tukey $(p \leq 0,05)$. Letras minúsculas: comparação de médias dentro de cada linha pelo teste de Tukey $(p \leq 0,05)$.

A variação no grau de umidade das sementes após os períodos de envelhecimento (Tabela 10) foi de até 0,7 pontos percentuais entre lotes de mesmo cultivar, estando abaixo dos limites toleráveis. Essa variação foi inferior à ocorrida após os períodos de envelhecimento acelerado realizado pelo procedimento tradicional (Tabela 8). Uma possível explicação para este fato é que a exposição das sementes a soluções saturadas de sais durante a 
realização do teste de envelhecimento acelerado, as quais reduzem a umidade relativa do ambiente no interior dos compartimentos individuais $(\mathrm{NaCl}-76 \%$ UR, $\mathrm{KCl}-87 \%$ UR ou $\mathrm{NaBr}-55 \%$ UR), retardam a absorção de água pelas sementes (Jianhua \& McDonald, 1996), sendo uma alternativa interessante para a avaliação do vigor de sementes de hortaliças, que em geral são pequenas e absorvem água mais rápida e desuniformemente, resultando em comportamento variável entre as sementes da amostra avaliada.

Tabela 10. Dados médios (\%) de grau de umidade de lotes de sementes dos cultivares Gigante Siculo, Cometa e Saxa, obtidos em testes de envelhecimento acelerado com solução saturada de $\mathrm{NaCl}$, obtidos após a exposição a três períodos, a $41^{\circ} \mathrm{C}$ e $45^{\circ} \mathrm{C}$

\begin{tabular}{lccccccc}
\hline Cultivares & Lotes & \multicolumn{3}{c}{$\mathbf{4 1}^{\circ} \mathbf{C}$} & & & $\mathbf{4 5}{ }^{\circ} \mathbf{C}$ \\
& & $\mathbf{4 8 h}$ & $\mathbf{7 2 h}$ & $\mathbf{9 6 h}$ & $\mathbf{4 8 h}$ & $\mathbf{7 2 h}$ & $\mathbf{9 6 h}$ \\
\hline \multirow{2}{*}{ Gigante } & 1 & 9,6 & 9,2 & 9,8 & 9,5 & 9,4 & 9,4 \\
Siculo & 2 & 9,7 & 9,3 & 9,7 & 9,4 & 9,4 & 9,3 \\
& 3 & 9,8 & 9,4 & 9,9 & 9,6 & 9,4 & 9,5 \\
& 4 & 9,4 & 9,2 & 9,6 & 9,3 & 9,3 & 9,3 \\
& 5 & 9,5 & 9,5 & 9,7 & 9,5 & 9,3 & 9,5 \\
Cometa & 6 & 9,7 & 9,6 & 9,6 & 9,6 & 9,5 & 9,7 \\
& 7 & 9,6 & 9,4 & 9,6 & 9,8 & 9,5 & 10,1 \\
& 8 & 9,8 & 9,9 & 9,9 & 9,9 & 9,7 & 9,9 \\
Saxa & 9 & 9,9 & 10,0 & 9,9 & 9,9 & 9,8 & 9,2 \\
\hline
\end{tabular}

Para o cultivar Saxa, o procedimento $45^{\circ} \mathrm{C} / 96 \mathrm{~h}$ no teste de envelhecimento acelerado com solução saturada de $\mathrm{NaCl}$ foi o único que permitiu diferenciar lotes e seguiu a classificação observada para os mesmos na avaliação de primeira contagem e percentagem final de germinação, ou seja, 
só diferenciou lotes que já haviam sido previamente separados no teste padrão de germinação, que é realizado sob condições ambientais favoráveis.

É interessante ressaltar que esse procedimento $\left(96 \mathrm{~h}\right.$ a $\left.45^{\circ} \mathrm{C}\right)$ não houve redução drástica dos percentuais de germinação quando comparado a mesma combinação no procedimento tradicional (Tabela 7), pois a utilização de solução saturada de $\mathrm{NaCl}$ implica em menor grau de umidade das sementes após o teste, quando comparado ao procedimento tradicional, havendo assim redução na taxa de deterioração das sementes.

Com relação ao cultivar Cometa, os resultados não foram satisfatórios, pois o teste promoveu diferentes classificações para os lotes estudados, sem consistência nos dados. Ë importante frisar que este teste foi desenvolvido, inicialmente para reduzir os efeitos negativos da exposição direta das sementes à elevada umidade relativa do ar nas câmaras de envelhecimento acelerado, que promovem muitas vezes reduções excessivas no desempenho de sementes pequenas, além de aumento na incidência de patógenos, porém não se deve considerar que esse teste será eficiente para todas as espécies estudadas. Neste contexto, o teste de envelhecimento acelerado com solução saturada de $\mathrm{NaCl}$ não foi adequado para diferenciar os lotes dos cultivares estudados.

\subsection{Deterioração controlada}

Os resultados referentes ao teste de deterioração controlada a $45^{\circ} \mathrm{C}$, durante 24 horas, utilizando-se grau de umidade das sementes ajustado artificialmente para três níveis diferentes, 20\%,22\% e $24 \%$, através do método da atmosfera úmida (Rossetto et al., 1995), são apresentados na Tabela 11.

Os resultados do teste de deterioração controlada quando o grau de umidade foi ajustado para $20 \%$ não revelaram diferença de potencial fisiológico entre os quatro lotes estudados do cultivar Gigante Siculo, à semelhança do 
ocorrido na caracterização inicial dos lotes (Tabela 6) e envelhecimento acelerado com solução saturada de $\mathrm{NaCl}$ (Tabela 9). Quando o grau de umidade foi ajustado para $22 \%$, o lote 3 destacou-se como o de melhor e o lote 1 como o de pior desempenho. Com grau de umidade ajustado para $24 \%$, o lote 4 apresentou-se como de qualidade inferior aos demais, ao contrário do ocorrido no teste de envelhecimento acelerado tradicional (Tabela 7), destacando o lote 3 como o de maior potencial fisiológico e os lotes 1 e 2 com desempenho intermediário.

Para o cultivar Cometa, na deterioração controlada com grau de umidade ajustado para $20 \%$, o lote 6 apresentou-se superior aos demais, sendo o lote 5 intermediário e o lote 7 de menor potencial fisiológico; com grau de umidade ajustado para $22 \%$, o teste de deterioração controlada não apontou diferenças de potencial fisiológico entre os três lotes estudados desse cultivar; com grau de umidade ajustado para $24 \%$, os lotes 5 e 6 não diferiram entre si e apresentaram-se superiores ao lote 7.

Para o cultivar Saxa, a deterioração controlada de sementes com $20 \%$ e $22 \%$ de água indicou o lote 8 como de maior potencial fisiológico quando comparado ao lote 9 , em concordância ao que foi observado nos testes de envelhecimento acelerado tradicional a $41^{\circ} \mathrm{C}$; 0 teste realizado em sementes com $24 \%$ de água indicou o lote 9 como de maior potencial fisiológico quando comparado ao lote 8 , em conformidade com os resultados de germinação e primeira contagem.

Os dados referentes ao grau de umidade das sementes após o teste de deterioração controlada são apresentados na Tabela 12. Verificou-se que esse parâmetro variou de 0,0 a 0,9 pontos percentuais entre lotes do mesmo cultivar, situando-se dentro de limites toleráveis. 
Tabela 11. Dados médios (\%) obtidos em testes de deterioração controlada de sementes dos cultivares Gigante Siculo, Cometa e Saxa $\left(45^{\circ} \mathrm{C} / 24 \mathrm{~h}\right)$, com três graus de umidade

\begin{tabular}{|c|c|c|c|c|}
\hline Cultivares & Lotes & $20 \%$ & $22 \%$ & $24 \%$ \\
\hline \multirow{3}{*}{ Gigante Siculo } & 1 & $87 A^{*}$ & $80 \mathrm{Ba}$ & $81 \mathrm{Ba}$ \\
\hline & 2 & 92Aa & $86 \mathrm{ABb}$ & 88ABab \\
\hline & 3 & 88Aa & 92Aa & 92Aa \\
\hline \multirow[b]{2}{*}{ C.V. $(\%)$} & 4 & 91Aa & $88 \mathrm{ABa}$ & $62 \mathrm{Cb}$ \\
\hline & & 4,98 & & \\
\hline \multirow{3}{*}{ Cometa } & 5 & $85 \mathrm{ABa}$ & 85Aa & 86Aa \\
\hline & 6 & 90Aa & 88Aa & 89Aa \\
\hline & 7 & $76 \mathrm{Bb}$ & 87Aa & $76 \mathrm{Bb}$ \\
\hline C.V. (\%) & & 5,67 & & \\
\hline \multirow[t]{2}{*}{ Saxa } & 8 & 88Aa & $76 \mathrm{Ab}$ & $50 \mathrm{Bc}$ \\
\hline & 9 & $68 \mathrm{Ba}$ & $51 \mathrm{Bb}$ & $59 A b$ \\
\hline C.V. $(\%)$ & & 5,06 & & \\
\hline
\end{tabular}


Tabela 12. Dados médios (\%) de grau de umidade obtidos em testes de deterioração controlada de sementes dos cultivares Gigante Siculo, Cometa e Saxa $\left(45^{\circ} \mathrm{C} / 24 \mathrm{~h}\right)$, com três graus de umidade

\begin{tabular}{lcccc}
\hline Cultivares & Lotes & $\mathbf{2 0 \%}$ & $\mathbf{2 2 \%}$ & $\mathbf{2 4 \%}$ \\
\hline \multirow{3}{*}{ Gigante Siculo } & 1 & 20,0 & 21,7 & 23,5 \\
& 2 & 20,0 & 22,1 & 24,1 \\
& 3 & 20,4 & 21,7 & 24,1 \\
Cometa & 4 & 20,0 & 22,0 & 23,9 \\
& 5 & & & \\
& 6 & 20,2 & 21,5 & 23,8 \\
& 7 & 20,4 & 22,3 & 23,9 \\
Saxa & & 20,1 & 21,8 & 24,0 \\
& 8 & 20,3 & 22,4 & 23,5 \\
& 9 & 20,3 & 21,7 & 24,4 \\
\hline
\end{tabular}

Os resultados obtidos na deterioração controlada quando o grau de umidade foi ajustado para 20 e $22 \%$ não permitiram a diferenciação dos lotes de todos os cultivares estudados concomitantemente. Quando o teor de água foi ajustado para $24 \%$, houve separação dos lotes, porém resultando em classificação diferente daquelas obtidas durante a caracterização inicial dos lotes e com o teste de envelhecimento acelerado tradicional.

\subsection{Condutividade elétrica}

Os resultados do teste de condutividade elétrica, envolvendo as combinações de número de sementes e volumes de água destilada nos diferentes períodos de embebição, são apresentados nas Tabelas de 13 a 15. 
A análise dos dados permitiu verificar que, de maneira geral, para o período de embebição de 1 hora em todas as combinações de número de sementes e volumes de água destilada, não houve diferenciação entre os lotes dos três cultivares estudados, exceto para o cultivar Gigante Siculo nas combinações de 50 sementes $/ 25 \mathrm{~mL} / 25^{\circ} \mathrm{C}$, indicando o lote 4 como de menor potencial fisiológico quando comparado aos demais; e para o cultivar Cometa na combinação de 50 sementes $/ 25 \mathrm{~mL} / 25^{\circ} \mathrm{C}$, que indicou o lote 7 como de menor potencial fisiológico quando comparado aos demais.

A análise dos dados permitiu verificar que, de maneira geral, para o cultivar Gigante Siculo, as combinações de número de sementes e volumes de água destilada nos diferentes períodos de embebição que mostraram diferenças de potencial fisiológico entre os lotes estudados indicaram o lote 4 como de qualidade inferior aos demais. Essa tendência é a mesma obtida no teste de deterioração controlada com grau de umidade ajustado para $24 \%$ (Tabela 11), ao contrário do envelhecimento acelerado tradicional, que em linhas gerais, apontou o lote 4 como superior aos demais (Tabela 7).

Os resultados obtidos nos testes de condutividade elétrica indicaram diferentes separações entre os lotes do cultivar Cometa. As combinações de 50 sementes $/ 25 \mathrm{~mL} / 25^{\circ} \mathrm{C}$ nos períodos de $1,2,4$ e 6 horas e 25 sementes $/ 50 \mathrm{~mL} / 25^{\circ} \mathrm{C}$ nos períodos de 1 e 2 horas apontaram o lote 7 como inferior aos demais, enquanto a combinação de 50 sementes $/ 75 \mathrm{~mL} / 25^{\circ} \mathrm{C}$ no período de 6 horas apontou o lote 6 como de menor potencial fisiológico comparados aos demais.

Para o cultivar Saxa, a maioria das combinações de número de sementes e volumes de água destilada nos diferentes períodos de embebição não promoveu diferenciação entre os lotes estudados, o que pode indicar que o teste de condutividade elétrica pode não ser sensível para detectar diferenças de potencial fisiológico entre tais lotes. A combinação de 25 sementes $/ 25 \mathrm{~mL} / 25^{\circ} \mathrm{C}$ no período de 6 horas indicou o lote 9 como inferior ao lote 8 , assim como no teste de envelhecimento acelerado tradicional, para a 
maior parte dos binômios temperatura/período de exposição estudados (Tabela 7). Entretanto, as combinações de 25 sementes $/ 75 \mathrm{~mL} / 25^{\circ} \mathrm{C}$ no período de 6 horas e 50 sementes $/ 75 \mathrm{~mL} / 25^{\circ} \mathrm{C}$ no período de 6 horas apontaram o lote 8 inferior ao lote 9.

Os resultados obtidos com o teste de condutividade elétrica para os cultivares em estudo, nas diferentes combinações de número de sementes e volumes de água destilada e nos diferentes períodos de embebição, indicaram um aumento progressivo das leituras com o decorrer dos períodos de embebição, o que concorda com as observações de Loeffler et al. (1988), Marcos Filho et al. (1990) e Dias et al. (1996). A embebição das sementes em água destilada nos volumes estudados por períodos superiores a 6 horas levou à emissão da raiz primária, motivo pelo qual o teste não foi realizado para os períodos de embebição de 8, 16 e 24 horas. 
Tabela 13. Dados médios ( $\mu \mathrm{S} / \mathrm{cm} . \mathrm{g}$ ) obtidos em testes de condutividade elétrica de lotes de sementes dos cultivares Gigante Siculo, Cometa e Saxa ( 25 ou 50 sementes embebidas em $25 \mathrm{~mL}$ de $\mathrm{H}_{2} \mathrm{O}$ destilada, a $25^{\circ} \mathrm{C}$ )

\begin{tabular}{|c|c|c|c|c|c|}
\hline \multirow{2}{*}{ Cultivares } & \multirow{2}{*}{ Lotes } & \multicolumn{4}{|c|}{ Períodos (h) } \\
\hline & & 1 & 2 & 4 & 6 \\
\hline \multirow{5}{*}{ Gigante Siculo } & & & 25 semente & $5 \mathrm{~mL} / 25^{\circ} \mathrm{C} \ldots$. & \\
\hline & 1 & $109,76 \mathrm{Aa}^{*}$ & $114,38 \mathrm{Aab}$ & $149,13 \mathrm{Abc}$ & $183,25 A c$ \\
\hline & 2 & $100,53 \mathrm{Aa}$ & 119,20Aab & $151,83 A b c$ & $176,85 \mathrm{Ac}$ \\
\hline & 3 & $112,67 \mathrm{Aa}$ & $137,15 \mathrm{Aa}$ & $181,32 \mathrm{ABb}$ & $195,76 \mathrm{Ab}$ \\
\hline & 4 & $114,02 \mathrm{Aa}$ & $185,13 \mathrm{Bb}$ & $214,78 \mathrm{Bba}$ & $236,99 B c$ \\
\hline \multirow[t]{2}{*}{ C.V. $(\%)$} & & 13,30 & & & \\
\hline & 5 & $92,82 \mathrm{Aa}$ & $110,72 \mathrm{Aa}$ & $156,31 \mathrm{Ab}$ & $176,27 \mathrm{Ab}$ \\
\hline \multirow[t]{2}{*}{ Cometa } & 6 & $96,57 \mathrm{Aa}$ & $102,76 \mathrm{Aa}$ & $157,90 \mathrm{Ab}$ & $170,66 \mathrm{Ab}$ \\
\hline & 7 & $92,07 \mathrm{Aa}$ & $96,18 \mathrm{Aa}$ & $154,27 A b$ & $169,61 \mathrm{Ab}$ \\
\hline \multirow[t]{2}{*}{ C.V. $(\%)$} & & 9,62 & & & \\
\hline & 8 & $103,54 \mathrm{Aa}$ & $120,96 \mathrm{Aa}$ & $125,45 \mathrm{Aa}$ & $142,89 \mathrm{Aa}$ \\
\hline Saxa & 9 & $108,61 \mathrm{Aa}$ & $119,30 \mathrm{Aab}$ & $153,76 \mathrm{Abc}$ & $191,32 \mathrm{Bc}$ \\
\hline \multirow[t]{3}{*}{ C.V. $(\%)$} & & 16,44 & & & \\
\hline & & \multicolumn{4}{|c|}{50 sementes $/ 25 \mathrm{~mL} / 25^{\circ} \mathrm{C}$} \\
\hline & 1 & $100,53 \mathrm{Aa}$ & $137,88 \mathrm{Ab}$ & $159,57 \mathrm{Bc}$ & $174,35 \mathrm{Bc}$ \\
\hline Gigante & 2 & $95,39 \mathrm{Aa}$ & $131,45 \mathrm{Ab}$ & $152,60 \mathrm{ABc}$ & $165,40 \mathrm{ABc}$ \\
\hline \multirow[t]{2}{*}{ Siculo } & 3 & $101,84 \mathrm{Aa}$ & $126,74 \mathrm{Ab}$ & $140,04 \mathrm{Abc}$ & $154,95 \mathrm{Ac}$ \\
\hline & 4 & $139,11 \mathrm{Ba}$ & $175,32 \mathrm{Bb}$ & $202,79 \mathrm{Cc}$ & $225,99 \mathrm{Cd}$ \\
\hline \multirow[t]{2}{*}{ C.V. $(\%)$} & & 6,38 & & & \\
\hline & 5 & $108,39 \mathrm{Aa}$ & $130,61 \mathrm{Ab}$ & $152,70 \mathrm{Ac}$ & $168,05 \mathrm{Ac}$ \\
\hline \multirow[t]{2}{*}{ Cometa } & 6 & $107,99 \mathrm{Aa}$ & $135,90 \mathrm{ABb}$ & $163,77 \mathrm{ABc}$ & $180,75 \mathrm{ABd}$ \\
\hline & 7 & $125,94 \mathrm{Ba}$ & $148,63 \mathrm{Bb}$ & $171,26 \mathrm{Bc}$ & $190,38 \mathrm{Bd}$ \\
\hline \multirow[t]{2}{*}{ C.V. (\%) } & & 5,70 & & & \\
\hline & 8 & $107,34 \mathrm{Aa}$ & $130,77 \mathrm{Ab}$ & $154,12 \mathrm{Ac}$ & $172,33 \mathrm{Ac}$ \\
\hline Saxa & 9 & $103,69 \mathrm{Aa}$ & $127,61 \mathrm{Ab}$ & $151,45 A c$ & $168,42 A c$ \\
\hline C.V. $(\%)$ & & 7,13 & & & \\
\hline
\end{tabular}

*Letras maiúsculas: comparação de médias dentro de cada coluna pelo teste de Tukey $(p \leq 0,05)$. Letras minúsculas: comparação de médias dentro de cada linha pelo teste de Tukey $(p \leq 0,05)$. 
Tabela 14. Dados médios ( $\mu \mathrm{S} / \mathrm{cm} . \mathrm{g}$ ) obtidos em testes de condutividade elétrica de lotes de sementes dos cultivares Gigante Siculo, Cometa e Saxa (25 ou 50 sementes embebidas em $50 \mathrm{~mL}$ de $\mathrm{H}_{2} \mathrm{O}$ destilada, a $25^{\circ} \mathrm{C}$ )

\begin{tabular}{|c|c|c|c|c|c|}
\hline \multirow{2}{*}{ Cultivares } & \multirow{2}{*}{ Lotes } & \multicolumn{4}{|c|}{ Períodos (h) } \\
\hline & & 1 & 2 & 4 & 6 \\
\hline & & \multicolumn{4}{|c|}{25 sementes $/ 50 \mathrm{~mL} / 25^{\circ} \mathrm{C}$} \\
\hline \multirow{4}{*}{ Gigante Siculo } & 1 & $57,29 \mathrm{Aa}^{*}$ & $69,73 \mathrm{Aab}$ & $81,01 \mathrm{Abc}$ & $89,19 A c$ \\
\hline & 2 & $58,37 \mathrm{Aa}$ & $71,44 \mathrm{Aa}$ & $86,17 \mathrm{ABb}$ & $91,92 \mathrm{Ab}$ \\
\hline & 3 & $64,57 \mathrm{Aa}$ & $80,36 \mathrm{ABb}$ & $91,96 \mathrm{ABbc}$ & $100,38 A c$ \\
\hline & 4 & $69,60 \mathrm{Aa}$ & $86,59 \mathrm{Bb}$ & $96,81 \mathrm{Bb}$ & $100,28 A b$ \\
\hline \multirow[t]{2}{*}{ C.V. $(\%)$} & & 9,65 & & & \\
\hline & 5 & $53,73 \mathrm{Aa}$ & $67,83 \mathrm{Ab}$ & $85,56 \mathrm{Ac}$ & $87,38 \mathrm{Ac}$ \\
\hline \multirow[t]{2}{*}{ Cometa } & 6 & $50,22 \mathrm{Aa}$ & $62,82 \mathrm{Ab}$ & $78,10 \mathrm{Ac}$ & $84,83 \mathrm{Ac}$ \\
\hline & 7 & $66,32 \mathrm{Ba}$ & $79,98 \mathrm{Bb}$ & $87,93 \mathrm{Ab}$ & $89,97 \mathrm{Ab}$ \\
\hline \multirow[t]{2}{*}{ C.V. $(\%)$} & & 8,73 & & & \\
\hline & 8 & $60,76 \mathrm{Aa}$ & $73,78 \mathrm{Aa}$ & $90,11 \mathrm{Ab}$ & $98,71 \mathrm{Ab}$ \\
\hline Saxa & 9 & $54,31 \mathrm{Aa}$ & $67,61 \mathrm{Aab}$ & $80,60 \mathrm{Abc}$ & $88,69 A c$ \\
\hline \multirow[t]{3}{*}{ C.V. $(\%)$} & & 9,40 & & & \\
\hline & & \multicolumn{4}{|c|}{50 sementes $/ 50 \mathrm{~mL} / 25^{\circ} \mathrm{C}$} \\
\hline & 1 & $50,49 \mathrm{Aa}$ & $54,77 \mathrm{Aa}$ & $74,23 \mathrm{Ab}$ & $80,75 \mathrm{Ab}$ \\
\hline \multirow{3}{*}{ Gigante Siculo } & 2 & $50,14 \mathrm{Aa}$ & $58,69 A b a b$ & $74,90 \mathrm{Abc}$ & $80,82 \mathrm{Ac}$ \\
\hline & 3 & $50,53 \mathrm{Aa}$ & $63,16 \mathrm{Abab}$ & $75,33 \mathrm{Abc}$ & $86,17 \mathrm{ABC}$ \\
\hline & 4 & $54,24 \mathrm{Aa}$ & $76,99 \mathrm{Bb}$ & $94,72 \mathrm{Bbc}$ & $104,26 \mathrm{Bc}$ \\
\hline \multirow[t]{2}{*}{ C.V. (\%) } & & 14,37 & & & \\
\hline & 5 & $45,31 \mathrm{Aa}$ & $53,15 \mathrm{Aa}$ & $73,90 \mathrm{Ab}$ & $82,32 \mathrm{Ab}$ \\
\hline \multirow[t]{2}{*}{ Cometa } & 6 & $47,20 \mathrm{Aa}$ & $59,45 \mathrm{Ab}$ & $77,97 \mathrm{Ac}$ & $89,11 \mathrm{Ac}$ \\
\hline & 7 & $45,15 \mathrm{Aa}$ & $63,05 \mathrm{Ab}$ & $73,89 A b c$ & $83,81 \mathrm{Ac}$ \\
\hline \multirow[t]{2}{*}{ C.V. (\%) } & & 9,11 & & & \\
\hline & 8 & $51,62 \mathrm{Aa}$ & $57,39 \mathrm{Aa}$ & $59,38 \mathrm{Aa}$ & $87,45 A b$ \\
\hline Saxa & 9 & $50,19 \mathrm{Aa}$ & 55,33Aab & $62,51 \mathrm{Ab}$ & $85,95 \mathrm{Ac}$ \\
\hline C.V. (\%) & & 6,87 & & & \\
\hline
\end{tabular}

*Letras maiúsculas: comparação de médias dentro de cada coluna pelo teste de Tukey $(p \leq 0,05)$. Letras minúsculas: comparação de médias dentro de cada linha pelo teste de Tukey $(p \leq 0,05)$. 
Tabela 15. Dados médios ( $\mu \mathrm{S} / \mathrm{cm} . \mathrm{g}$ ) obtidos em testes de condutividade elétrica de lotes de sementes dos cultivares Gigante Siculo, Cometa e Saxa ( 25 ou 50 sementes embebidas em $75 \mathrm{~mL}$ de $\mathrm{H} 2 \mathrm{O}$ destilada, a $25^{\circ} \mathrm{C}$ )

\begin{tabular}{|c|c|c|c|c|c|}
\hline \multirow{2}{*}{ Cultivares } & \multirow{2}{*}{ Lotes } & \multicolumn{4}{|c|}{ Períodos (h) } \\
\hline & & 1 & 2 & 4 & 6 \\
\hline \multirow{5}{*}{ Gigante Siculo } & & $\cdots \cdots \cdots \cdots \cdots$ & 25 semente & $\mathrm{mL} / 25^{\circ} \mathrm{C} \ldots$ & $\ldots \ldots \ldots \ldots \ldots$ \\
\hline & 1 & $47,83 \mathrm{Aa}^{*}$ & $56,85 \mathrm{Aab}$ & $67,13 \mathrm{Abc}$ & $75,88 \mathrm{Ac}$ \\
\hline & 2 & $42,07 \mathrm{Aa}$ & $50,67 \mathrm{Aab}$ & $59,76 \mathrm{Aab}$ & $66,54 \mathrm{Ab}$ \\
\hline & 3 & $45,82 \mathrm{Aa}$ & $56,01 \mathrm{Aab}$ & $68,27 \mathrm{Abc}$ & $75,67 A c$ \\
\hline & 4 & 49,88Aa & 61,80Aab & $74,94 \mathrm{Abc}$ & $83,39 A c$ \\
\hline \multirow[t]{2}{*}{ C.V. $(\%)$} & & 16,46 & & & \\
\hline & 5 & $42,36 \mathrm{Aa}$ & $51,58 \mathrm{Ab}$ & $63,26 \mathrm{Ac}$ & $68,93 \mathrm{Ac}$ \\
\hline \multirow[t]{2}{*}{ Cometa } & 6 & $38,97 \mathrm{Aa}$ & $49,10 A b$ & $59,95 \mathrm{Ac}$ & $66,24 A c$ \\
\hline & 7 & $41,43 \mathrm{Aa}$ & $51,04 \mathrm{Ab}$ & $61,20 \mathrm{Ac}$ & $66,98 \mathrm{Ac}$ \\
\hline \multirow[t]{2}{*}{ C.V. (\%) } & & 6,16 & & & \\
\hline & 8 & $43,09 A a$ & $52,47 \mathrm{Aab}$ & $62,87 \mathrm{Abc}$ & $70,75 \mathrm{Bc}$ \\
\hline Saxa & 9 & $39,46 \mathrm{Aa}$ & 47,00Aab & $55,76 \mathrm{Abc}$ & $62,46 A c$ \\
\hline \multirow[t]{3}{*}{ C.V. $(\%)$} & & 10,46 & & & \\
\hline & & ................. & 50 semente & $\mathrm{mL} / 25^{\circ} \mathrm{C} \ldots$. & ................ \\
\hline & 1 & $37,78 \mathrm{Aa}$ & $47,34 \mathrm{Ab}$ & $51,55 A b$ & $53,19 A b$ \\
\hline \multirow{3}{*}{ Gigante Siculo } & 2 & $40,96 \mathrm{Aa}$ & $48,85 A a b$ & $54,32 \mathrm{Ab}$ & $55,97 \mathrm{Ab}$ \\
\hline & 3 & $39,73 \mathrm{Aa}$ & $49,05 A b$ & $53,78 \mathrm{Ab}$ & $55,78 \mathrm{Ab}$ \\
\hline & 4 & $45,26 \mathrm{Aa}$ & 53,56Aab & $56,86 A b$ & $68,29 B c$ \\
\hline \multirow[t]{2}{*}{ C.V. (\%) } & & 9,64 & & & \\
\hline & 5 & $37,15 \mathrm{Aa}$ & $46,45 A b$ & $51,16 \mathrm{Ab}$ & $52,31 \mathrm{Ab}$ \\
\hline \multirow[t]{2}{*}{ Cometa } & 6 & $37,24 \mathrm{Aa}$ & $45,73 \mathrm{Ab}$ & $48,30 A b$ & $59,96 \mathrm{Bc}$ \\
\hline & 7 & $39,74 \mathrm{Aa}$ & 46,35Aab & $49,19 A b$ & $50,06 \mathrm{Ab}$ \\
\hline \multirow[t]{2}{*}{ C.V. $(\%)$} & & 9,46 & & & \\
\hline & 8 & $39,20 \mathrm{Aa}$ & $48,40 A b$ & $56,81 \mathrm{Ac}$ & $60,46 \mathrm{Bd}$ \\
\hline Saxa & 9 & $37,36 \mathrm{Aa}$ & $47,92 A b$ & $55,00 A c$ & $56,91 \mathrm{Ac}$ \\
\hline C.V. $(\%)$ & & 3,44 & & & \\
\hline
\end{tabular}


O teste de condutividade elétrica utilizando 50 sementes $/ 75 \mathrm{~mL} / 25^{\circ} \mathrm{C}$ promoveu a separação de todos os lotes estudados, ainda que de maneira diversa da obtida durante a caracterização inicial dos lotes e no envelhecimento acelerado tradicional a $41^{\circ} \mathrm{C} / 48$ horas. Devido a sua sensibilidade, facilidade de execução, rapidez de resultados e possibilidade de avaliação do vigor antes da perda do poder germinativo (Marcos Filho, 1999a), este teste consiste em alternativa interessante para avaliação do vigor de sementes de rabanete, necessitando porém de estudos adicionais.

\subsection{Lixiviação de potássio}

Os dados referentes ao teste de lixiviação de potássio, envolvendo as combinações de número de sementes e volumes de água destilada, nos diferentes períodos de embebição, são apresentados nas Tabelas 16 a 18. Grande parte das combinações utilizadas no teste de lixiviação de potássio não detectou diferenças entre os lotes avaliados dos cultivares Cometa e Saxa.

O teste de lixiviação de potássio nas combinações que permitiram a separação dos lotes do cultivar Gigante Siculo, em sua maioria, o lote 4 como sendo o de menor potencial fisiológico quando comparado aos demais, à semelhança dos resultados obtidos no teste de condutividade elétrica (Tabelas 13 a 15) e deterioração controlada com grau de umidade ajustado para $24 \%$ (Tabela 11).

Para o cultivar Cometa, os resultados de lixiviação de potássio nas combinações de 50 sementes $/ 50 \mathrm{~mL} / 25^{\circ} \mathrm{C}$ no período de 90 minutos; 100 sementes $/ 50 \mathrm{~mL} / 25^{\circ} \mathrm{C}$ nos períodos de 30 e 60 minutos; e 100 sementes $/ 75 \mathrm{~mL} / 25^{\circ} \mathrm{C}$ nos períodos de 30, 60 e 120 minutos indicaram o lote 7 como inferior aos demais; Para esse cultivar, a combinação de 50 sementes $/ 75 \mathrm{~mL} / 25^{\circ} \mathrm{C}$ no período de 180 minutos indicou o lote 6 como inferior aos demais. 
Apenas as combinações de 50 sementes $/ 25 \mathrm{~mL} / 25^{\circ} \mathrm{C}$ nos períodos de 150 e 180 minutos e 100 sementes $/ 25 \mathrm{~mL} / 25^{\circ} \mathrm{C}$ no período de 150 minutos apontaram diferenças entre os lotes estudados para o cultivar Saxa, sendo que o lote 9 apresentou-se como de melhor qualidade quando comparado ao lote 8 , em concordância ao que foi observado no teste de deterioração controlada com grau de umidade ajustado para $24 \%$ (Tabela 11) e no teste de condutividade elétrica nas combinações de 25 sementes $/ 75 \mathrm{~mL} / 25^{\circ} \mathrm{C}$ no período de 6 horas (Tabela 15) e 50 sementes $/ 75 \mathrm{~mL} / 25^{\circ} \mathrm{C}$ no período de 6 horas (Tabela 15).

As combinações de 50 sementes $/ 25 \mathrm{~mL} / 30$ minutos, 50 sementes $/ 50 \mathrm{~mL} / 30,60,90,120$ e 150 minutos, 100 sementes $/ 50 \mathrm{~mL} / 30$ minutos, 50 sementes $/ 75 \mathrm{~mL} / 30$ minutos em todos os períodos de embebição estudados e 100 sementes $/ 75 \mathrm{~mL} / 30$ e 60 minutos para os três cultivares estudados; de 100 sementes/75mL/90 minutos para o cultivar Cometa; e de 100 sementes $/ 25 \mathrm{~mL} / 30$ minutos, 50 sementes $/ 50 \mathrm{~mL} / 180$ minutos e 100 sementes/75mL/120 minutos para o cultivar Saxa levaram a leituras baixas e demoradas, o que compromete a praticidade e aplicabilidade do teste de lixiviação de potássio. 
Tabela 16. Dados médios ( $\mathrm{ppm} / \mathrm{g}$ ) obtidos em testes de lixiviação de potássio em lotes de sementes dos cultivares Gigante Siculo, Cometa e Saxa (50 ou 100 sementes embebidas em $25 \mathrm{~mL}$ de $\mathrm{H}_{2} \mathrm{O}$ destilada, a $25^{\circ} \mathrm{C}$ )

\begin{tabular}{|c|c|c|c|c|c|c|c|}
\hline \multirow{2}{*}{ Cultivares } & \multirow{2}{*}{ Lotes } & \multicolumn{6}{|c|}{ Períodos (min) } \\
\hline & & 30 & 60 & 90 & 120 & 150 & 180 \\
\hline & & & & 50 semente & $25 \mathrm{~mL} / 25^{\circ} \mathrm{C}$. & & . \\
\hline & 1 & $504,41 \mathrm{Aa}^{*}$ & $871,64 \mathrm{Ab}$ & $1004,68 \mathrm{Abc}$ & $1138,44 \mathrm{Abcd}$ & $1214,30 \mathrm{Abcd}$ & $1250,02 \mathrm{ABd}$ \\
\hline Gigante & 2 & $529,34 \mathrm{Aa}$ & $892,51 \mathrm{Ab}$ & $1002,66 \mathrm{Abc}$ & $1100,13 \mathrm{Abcd}$ & $1196,98 \mathrm{Abcd}$ & $1242,83 \mathrm{ABd}$ \\
\hline \multirow[t]{2}{*}{ Siculo } & 3 & $652,33 \mathrm{Aa}$ & $876,83 A b$ & $990,45 \mathrm{Abc}$ & $1104,68 \mathrm{Ac}$ & $1152,42 A c$ & $1188,14 \mathrm{Ac}$ \\
\hline & 4 & $870,30 \mathrm{Ba}$ & 1043,61Aab & $1214,85 \mathrm{Bbc}$ & $1312,18 \mathrm{Bc}$ & $1370,98 \mathrm{Bc}$ & $1392,34 \mathrm{Bc}$ \\
\hline \multirow[t]{2}{*}{ C.V. (\%) } & & 9,77 & & & & & \\
\hline & 5 & $696,34 \mathrm{Aa}$ & $954,67 \mathrm{Aab}$ & $1132,90 \mathrm{Abc}$ & $1209,65 \mathrm{Abc}$ & $1272,56 \mathrm{Ac}$ & $1312,98 \mathrm{Ac}$ \\
\hline \multirow[t]{2}{*}{ Cometa } & 6 & $548,31 \mathrm{Aa}$ & $819,85 A b$ & $995,84 \mathrm{Abc}$ & $1086,78 \mathrm{Ac}$ & $1138,74 \mathrm{Ac}$ & $1182,51 \mathrm{Ac}$ \\
\hline & 7 & $757,30 \mathrm{Aa}$ & $897,87 A a b$ & $1037,11 \mathrm{Abc}$ & $1110,58 \mathrm{Abc}$ & $1207,88 \mathrm{Ac}$ & $1244,17 \mathrm{Ac}$ \\
\hline \multirow[t]{2}{*}{ C.V. (\%) } & & 12,34 & & & & & \\
\hline & 8 & $577,02 \mathrm{Aa}$ & $847,32 \mathrm{Ab}$ & $1044,99 \mathrm{Abc}$ & $1173,41 \mathrm{Ac}$ & $1410,79 \mathrm{Bd}$ & $1387,76 \mathrm{Bd}$ \\
\hline Saxa & 9 & $572,14 \mathrm{Aa}$ & $822,61 \mathrm{Ab}$ & $1005,37 \mathrm{Abc}$ & 1108,62 Acd & 1142,68 Acd & $1222,22 \mathrm{Ad}$ \\
\hline \multirow[t]{3}{*}{ C.V. (\%) } & & 9,51 & & & & & \\
\hline & & & & 100 sement & $\mathrm{s} / 25 \mathrm{~mL} / 25^{\circ} \mathrm{C}$. & & \\
\hline & 1 & $618,48 \mathrm{Aa}$ & $875,67 A b$ & $950,88 \mathrm{Abc}$ & $1002,29 A c$ & $1038,44 \mathrm{Ac}$ & $1034,64 \mathrm{Ac}$ \\
\hline Gigante & 2 & $615,07 \mathrm{Aa}$ & $874,25 A b$ & $957,96 \mathrm{Abc}$ & 1025,02 Acd & 1047,34 Acd & $1069,42 \mathrm{Ad}$ \\
\hline \multirow[t]{2}{*}{ Siculo } & 3 & $618,05 \mathrm{Aa}$ & $902,65 A b$ & $966,07 \mathrm{Abc}$ & 1035,76 Acd & $1088,15 \mathrm{Ad}$ & $1083,53 \mathrm{Ad}$ \\
\hline & 4 & $754,60 \mathrm{Ba}$ & $1038,79 \mathrm{Bb}$ & $1142,36 \mathrm{Bbc}$ & $1188,46 \mathrm{Bc}$ & $1247,63 \mathrm{Bc}$ & $1234,99 \mathrm{Bc}$ \\
\hline \multirow[t]{2}{*}{ C.V. (\%) } & & 5,41 & & & & & \\
\hline & 5 & $634,38 \mathrm{Aa}$ & $816,95 \mathrm{Ab}$ & $940,89 A b c$ & $978,68 A c$ & $1009,72 \mathrm{Ac}$ & $1015,36 \mathrm{Ac}$ \\
\hline \multirow[t]{2}{*}{ Cometa } & 6 & $609,00 \mathrm{Aa}$ & $801,34 \mathrm{Ab}$ & $906,15 A b c$ & $953,00 \mathrm{Abc}$ & $985,44 A c$ & $1004,64 \mathrm{Ac}$ \\
\hline & 7 & $725,97 \mathrm{Aa}$ & $900,98 \mathrm{Ab}$ & $981,35 \mathrm{Abc}$ & $1020,03 \mathrm{Abc}$ & $1063,66 \mathrm{Ac}$ & $1035,17 \mathrm{Abc}$ \\
\hline \multirow[t]{2}{*}{ C.V. (\%) } & & 8,24 & & & & & \\
\hline & 8 & $678,43 \mathrm{Aa}$ & $859,65 A b$ & $965,13 A c$ & $1010,85 \mathrm{Acd}$ & $1063,54 \mathrm{Bd}$ & $1056,40 \mathrm{Acd}$ \\
\hline Saxa & 9 & $678,94 \mathrm{Aa}$ & $811,18 A b$ & $921,77 \mathrm{Ac}$ & $958,43 A c$ & $987,56 \mathrm{Ac}$ & $1010,83 \mathrm{Ac}$ \\
\hline C.V. (\%) & & 4,76 & & & & & \\
\hline
\end{tabular}

*Letras maiúsculas: comparação de médias dentro de cada coluna pelo teste de Tukey $(p \leq$ $0,05)$. Letras minúsculas: comparação de médias dentro de cada linha pelo teste de Tukey $(p \leq 0,05)$. 
Tabela 17. Dados médios (ppm/g) obtidos em testes de lixiviação de potássio em lotes de sementes dos cultivares Gigante Siculo, Cometa e Saxa (50 ou 100 sementes embebidas em $50 \mathrm{~mL}$ de $\mathrm{H} 2 \mathrm{O}$ destilada, a $25^{\circ} \mathrm{C}$ )

\begin{tabular}{|c|c|c|c|c|c|c|c|}
\hline \multirow{2}{*}{ Cultivares } & \multirow{2}{*}{ Lotes } & \multicolumn{6}{|c|}{ Períodos (min) } \\
\hline & & 30 & 60 & 90 & 120 & 150 & 180 \\
\hline & & & & .50 sement & $/ 50 \mathrm{~mL} / 25^{\circ} \mathrm{C}$ & & \\
\hline & 1 & $602,12 \mathrm{Aa}^{*}$ & $916,92 \mathrm{Ab}$ & $1126,55 \mathrm{Abc}$ & 1291,26 Acd & 1415,65 Acd & $1508,79 \mathrm{ABd}$ \\
\hline Gigante & 2 & $644,13 \mathrm{Aa}$ & $915,23 \mathrm{Aab}$ & $1114,21 \mathrm{Abc}$ & 1243,94 Acd & 1365,76Acd & $1479,23 \mathrm{ABd}$ \\
\hline \multirow[t]{2}{*}{ Siculo } & 3 & $654,02 \mathrm{Aa}$ & $897,32 \mathrm{Ab}$ & $1158,65 \mathrm{Abc}$ & $1289,92 \mathrm{Acd}$ & $1382,82 \mathrm{Acd}$ & $1470,48 \mathrm{Ad}$ \\
\hline & 4 & $769,90 \mathrm{Aa}$ & $1048,70 \mathrm{Ab}$ & $1284,10 \mathrm{Abc}$ & $1507,92 \mathrm{Acd}$ & $1628,97 \mathrm{Ad}$ & $1743,30 \mathrm{Bd}$ \\
\hline \multirow[t]{2}{*}{ C.V. (\%) } & & 12,35 & & & & & \\
\hline & 5 & $555,90 \mathrm{Aa}$ & $803,27 A b$ & $955,94 \mathrm{Abc}$ & 1156,63 Acd & $1266,73 \mathrm{Ad}$ & $1344,80 \mathrm{Ad}$ \\
\hline \multirow[t]{2}{*}{ Cometa } & 6 & $575,23 \mathrm{Aa}$ & $801,39 A b$ & $929,25 \mathrm{Abc}$ & 1137,85 Acd & 1253,75Ade & $1388,64 \mathrm{Ae}$ \\
\hline & 7 & $680,92 \mathrm{Aa}$ & $891,64 \mathrm{Aa}$ & $1167,16 \mathrm{Bb}$ & $1298,71 \mathrm{Abc}$ & $1432,17 \mathrm{Acd}$ & $1527,16 \mathrm{Ad}$ \\
\hline \multirow[t]{2}{*}{ C.V. $(\%)$} & & 10,11 & & & & & \\
\hline & 8 & $642,63 \mathrm{Aa}$ & $876,23 \mathrm{Ab}$ & $995,82 \mathrm{Abc}$ & $1109,77 \mathrm{Acd}$ & 1250,05Ade & $1320,32 \mathrm{Ae}$ \\
\hline Saxa & 9 & $645,18 \mathrm{Aa}$ & $863,92 A b$ & $976,60 \mathrm{Abc}$ & 1083,85 Acd & 1185,67Ade & $1251,89 \mathrm{Ae}$ \\
\hline \multirow[t]{3}{*}{ C.V. $(\%)$} & & 7,24 & & & & & \\
\hline & & & & 100 semente & $/ 50 \mathrm{~mL} / 25^{\circ} \mathrm{C}$ & & \\
\hline & 1 & $702,30 \mathrm{Aa}$ & $974,89 A b$ & $1143,12 \mathrm{Ac}$ & 1242,11 Acd & 1335,87Ade & $1365,62 \mathrm{Ae}$ \\
\hline Gigante & 2 & $724,71 \mathrm{Aa}$ & $962,81 \mathrm{Ab}$ & $1145,17 \mathrm{Ac}$ & $1226,36 \mathrm{Ac}$ & $1347,53 \mathrm{Ad}$ & $1361,91 \mathrm{Ad}$ \\
\hline \multirow[t]{2}{*}{ Siculo } & 3 & $693,00 \mathrm{Aa}$ & $937,77 A b$ & $1108,64 \mathrm{Ac}$ & 1209,57 Acd & 1305,23Ade & $1350,79 \mathrm{Ae}$ \\
\hline & 4 & $834,38 \mathrm{Ba}$ & $1095,39 \mathrm{Bb}$ & $1281,90 \mathrm{Bc}$ & $1396,84 \mathrm{Bc}$ & $1535,61 \mathrm{Bd}$ & $1562,31 \mathrm{Bd}$ \\
\hline \multirow[t]{2}{*}{ C.V. $(\%)$} & & 4,92 & & & & & \\
\hline & 5 & $580,67 \mathrm{Aa}$ & $824,22 \mathrm{Ab}$ & $988,12 \mathrm{Ac}$ & $1089,91 \mathrm{Ad}$ & 1160,63Ade & $1226,59 \mathrm{Ae}$ \\
\hline \multirow[t]{2}{*}{ Cometa } & 6 & $614,59 \mathrm{Aa}$ & $845,92 \mathrm{ABb}$ & $1026,19 \mathrm{Ac}$ & $1141,88 \mathrm{Ad}$ & 1199,07Ade & $1251,50 \mathrm{Ae}$ \\
\hline & 7 & $689,19 \mathrm{Ba}$ & $895,93 \mathrm{Bb}$ & $1053,80 \mathrm{Ac}$ & 1137,60 Acd & 1177,95Ade & $1227,84 \mathrm{Ae}$ \\
\hline \multirow[t]{2}{*}{ C.V. (\%) } & & 4,02 & & & & & \\
\hline & 8 & $671,26 \mathrm{Aa}$ & $871,22 A b$ & $1061,49 \mathrm{Ac}$ & $1158,87 \mathrm{Acd}$ & 1216,91Ade & $1304,76 \mathrm{Ae}$ \\
\hline Saxa & 9 & $696,25 \mathrm{Aa}$ & $869,53 \mathrm{Ab}$ & $1018,12 \mathrm{Ac}$ & $1144,31 \mathrm{Ad}$ & 1215,53Ade & $1283,68 \mathrm{Ae}$ \\
\hline C.V. (\%) & & 5,16 & & & & & \\
\hline
\end{tabular}

*Letras maiúsculas: comparação de médias dentro de cada coluna pelo teste de Tukey $(p \leq$ $0,05)$. Letras minúsculas: comparação de médias dentro de cada linha pelo teste de Tukey $(p \leq 0,05)$. 
Tabela 18. Dados médios ( $\mathrm{ppm} / \mathrm{g}$ ) obtidos em testes de lixiviação de potássio em lotes de sementes dos cultivares Gigante Siculo, Cometa e Saxa (50 ou 100 sementes embebidas em $75 \mathrm{~mL}$ de $\mathrm{H} 2 \mathrm{O}$ destilada, a $25^{\circ} \mathrm{C}$ )

\begin{tabular}{|c|c|c|c|c|c|c|c|}
\hline \multirow{2}{*}{ Cultivares } & \multirow{2}{*}{ Lotes } & \multicolumn{6}{|c|}{ Períodos (min) } \\
\hline & & 30 & 60 & 90 & 120 & 150 & 180 \\
\hline & & & & 50 semente & $175 \mathrm{~mL} / 25^{\circ} \mathrm{C}$. & wan & . \\
\hline & 1 & $733,40 \mathrm{Aa}^{*}$ & $959,39 \mathrm{Abb}$ & $1135,71 \mathrm{ABbc}$ & $1306,84 \mathrm{BCcd}$ & 1472,79BCde & $1592,03 \mathrm{BCe}$ \\
\hline Gigante & 2 & $726,10 \mathrm{Aa}$ & 908,38 Abab & $1085,47 \mathrm{ABbc}$ & $1207,33 \mathrm{Abcd}$ & $1374,74 \mathrm{ABde}$ & $1490,73 \mathrm{ABe}$ \\
\hline \multirow[t]{2}{*}{ Siculo } & 3 & $658,41 \mathrm{Aa}$ & $640,61 \mathrm{Ab}$ & $1009,90 \mathrm{Abc}$ & 1129,85 Acd & 1208,74Ade & $1322,28 \mathrm{Ae}$ \\
\hline & 4 & $777,27 \mathrm{Aa}$ & $1051,70 \mathrm{Bb}$ & $1226,63 \mathrm{Bbc}$ & $1396,37 \mathrm{Ccd}$ & $1560,93 \mathrm{Cde}$ & $1720,31 \mathrm{Ce}$ \\
\hline \multirow[t]{2}{*}{ C.V. (\%) } & & 7,80 & & & & & \\
\hline & 5 & $519,62 A a$ & $809,97 \mathrm{Ab}$ & $967,61 \mathrm{Ac}$ & $1158,26 \mathrm{Ad}$ & $1306,14 \mathrm{Ae}$ & $1412,83 \mathrm{ABe}$ \\
\hline \multirow[t]{2}{*}{ Cometa } & 6 & $534,87 \mathrm{Aa}$ & $833,13 \mathrm{Ab}$ & $1041,21 \mathrm{Ac}$ & $1198,11 \mathrm{Ad}$ & $1350,25 \mathrm{Ae}$ & $1497,64 \mathrm{Bf}$ \\
\hline & 7 & $588,77 \mathrm{Aa}$ & $834,57 \mathrm{Ab}$ & $987,95 \mathrm{Ac}$ & $1174,93 \mathrm{Ad}$ & 1276,25Ade & $1376,02 \mathrm{Ae}$ \\
\hline \multirow[t]{2}{*}{ C.V. (\%) } & & 6,64 & & & & & \\
\hline & 8 & $648,29 \mathrm{Aa}$ & $852,87 \mathrm{Aab}$ & $1054,90 \mathrm{Abc}$ & 1247,91Acd & $1385,94 \mathrm{Ad}$ & $1463,82 \mathrm{Ad}$ \\
\hline Saxa & 9 & $631,27 \mathrm{Aa}$ & $830,47 \mathrm{Aab}$ & $972,72 A b c$ & 1161,40Acd & $1344,47 \mathrm{Ad}$ & $1422,95 \mathrm{Ad}$ \\
\hline \multirow[t]{3}{*}{ C.V. (\%) } & & 11,97 & & & & & \\
\hline & & ….............. & ………........ & ... 100 semente & $175 \mathrm{~mL} / 25^{\circ} \mathrm{C} \ldots$ & …… & 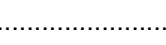 \\
\hline & 1 & $638,18 \mathrm{Aa}$ & $897,40 A b$ & $1149,07 \mathrm{Ac}$ & 1225,54 Acd & 1326,63Ade & $1444,75 \mathrm{Ae}$ \\
\hline Gigante & 2 & $629,40 \mathrm{Aa}$ & $885,26 \mathrm{Ab}$ & $1132,28 \mathrm{Ac}$ & 1232,73 Acd & 1333,20Ade & $1405,10 \mathrm{Ae}$ \\
\hline \multirow[t]{2}{*}{ Siculo } & 3 & $710,85 \mathrm{Aa}$ & $954,28 A b$ & $1161,29 A c$ & 1268,42 Acd & 1417,88Ade & $1492,69 \mathrm{Ae}$ \\
\hline & 4 & $760,42 \mathrm{Aa}$ & $1137,84 \mathrm{Bb}$ & $1337,68 \mathrm{Bc}$ & $1484,17 \mathrm{Bcd}$ & $1627,21 \mathrm{Bde}$ & $1740,96 \mathrm{Be}$ \\
\hline \multirow[t]{2}{*}{ C.V. $(\%)$} & & 6,78 & & & & & \\
\hline & 5 & $547,32 \mathrm{Aa}$ & $763,61 \mathrm{Ab}$ & $1019,65 A c$ & $1158,83 \mathrm{Abd}$ & 1250,78Ade & $1318,31 \mathrm{Ae}$ \\
\hline \multirow[t]{2}{*}{ Cometa } & 6 & $568,01 \mathrm{Aa}$ & $740,07 \mathrm{Ab}$ & $972,77 \mathrm{Ac}$ & $1067,78 \mathrm{Ac}$ & $1204,64 \mathrm{Ad}$ & $1272,64 \mathrm{Ad}$ \\
\hline & 7 & $707,08 \mathrm{Ba}$ & $909,49 \mathrm{Bb}$ & $1063,98 \mathrm{Ac}$ & $1193,09 \mathrm{Bd}$ & 1257,63Ade & $1339,19 \mathrm{Ae}$ \\
\hline \multirow[t]{2}{*}{ C.V. (\%) } & & 5,22 & & & & & \\
\hline & 8 & $664,02 \mathrm{Aa}$ & $877,73 \mathrm{Ab}$ & $1053,79 \mathrm{Ac}$ & 1198,76 Acd & 1287,29 Ade & $1372,86 \mathrm{Ae}$ \\
\hline Saxa & 9 & $702,48 \mathrm{Aa}$ & $821,03 \mathrm{Aa}$ & $1012,42 \mathrm{Ab}$ & $1147,22 \mathrm{Abc}$ & 1254,02 Acd & $1333,44 \mathrm{Ad}$ \\
\hline C.V. (\%) & & 6,23 & & & & & \\
\hline
\end{tabular}

*Letras maiúsculas: comparação de médias dentro de cada coluna pelo teste de Tukey ( $\mathrm{p} \leq$ $0,05)$. Letras minúsculas: comparação de médias dentro de cada linha pelo teste de Tukey $(p \leq 0,05)$.

As combinações de 50 sementes $/ 25 \mathrm{~mL} / 25^{\circ} \mathrm{C}$ nos períodos de 150 e 180 minutos e 100 sementes $/ 25 \mathrm{~mL} / 25^{\circ} \mathrm{C}$ no período de 150 minutos permitiram a diferenciação dos lotes estudados para os cultivares Gigante Siculo e Saxa. Neste teste, nenhuma combinação se destacou para separar os lotes dos três 
cultivares avaliados ao mesmo tempo. Entretanto, este teste, baseado no mesmo princípio do teste de condutividade elétrica, tem a vantagem de proporcionar informações sobre o potencial fisiológico dos lotes em período de tempo consideravelmente reduzido (Dias \& Marcos Filho, 1995), de maneira que estudos adicionais devem ser realizados para verificar a metodologia mais adequada para a condução do teste visando a avaliação do vigor de sementes de rabanete.

\subsection{Considerações finais}

As sementes de rabanete (Raphanus sativus L.) possuem elevado valor comercial e esta cultura, caracterizada por possuir ciclo muito curto (cerca de 30 dias), promover retorno rápido e ser relativamente rústica, é utilizada em grande número de pequenas propriedades dos cinturões verdes, com grande diversidade de cultivo de hortaliças, entre outras de ciclo mais longo, com épocas definidas de semeadura. Porém, existem poucos trabalhos a respeito da utilização de testes de vigor para estimar o potencial fisiológico de sementes dessa espécie, havendo demanda por informações que possam ser utilizadas em programas de controle de qualidade.

O teste de envelhecimento acelerado com procedimento tradicional, com destaque para a exposição das sementes a $41^{\circ} \mathrm{C}$ durante 48 horas, promoveu resultados interessantes e demonstrou diferenciar os lotes estudados de maneira satisfatória, enquanto o teste de envelhecimento acelerado com solução saturada de $\mathrm{NaCl}$ parece não ter causado estresse suficiente para a separação desses lotes. Também, a deterioração controlada não promoveu a diferenciação dos lotes utilizados na pesquisa de maneira satisfatória.

Os testes de condutividade elétrica e lixiviação de potássio mostraram-se como alternativas promissoras para a avaliação do vigor de sementes de 
rabanete, enfatizando a necessidade de estudos adicionais para determinação das metodologias mais adequadas.

É válido ressaltar que o trabalho foi conduzido com 4 lotes do cultivar Gigante Siculo, 3 lotes do cultivar Cometa e 2 lotes do cultivar Saxa, com o objetivo de verificar o comportamento dessas sementes submetidas a diferentes testes de vigor. A extrapolação dos resultados para outros cultivares da espécie em estudo necessita estudos complementares e comprovação dos procedimentos mais adequados. 


\section{CONCLUSÕES}

O teste de envelhecimento acelerado com procedimento tradicional, destacando o binômio temperatura/período de exposição de $41^{\circ} \mathrm{C} / 48$ horas, é suficientemente sensível para detectar diferenças entre lotes de sementes de rabanete.

Os testes de condutividade elétrica e lixiviação de potássio podem constituir alternativas promissoras para a avaliação do vigor de sementes de rabanete, mas há necessidade de estudos adicionais para determinação dos procedimentos mais adequados para sua condução. 


\section{REFERÊNCIAS BIBLIOGRÁFICAS}

ABDUL-BAKI, A.A. Biochemical aspects of seed vigour. HortScience, v.15, p.765-771, 1980.

ALSADON, A.; YULE, L.J.; POWELL, A.A. Influence of seed ageing on the germination, vigour and emergence in module trays of tomato and cucumber seeds. Seed Science and Technology, v.23, n.3, p.665-672, 1995.

ANDRADE, R.N.; SANTOS, D.S.B.; SANTOS FILHO, B.G.; MELLO, V.D.C. Correlação entre testes de vigor em sementes de cenoura armazenadas por diferentes períodos. Pesquisa Agropecuária Gaúcha, v.1, n.2, p.153-162, 1995.

ARGERICH, C.A.; BRADFORD, K.J. The effects of priming and ageing on seed vigour in tomato. Journal of Experimental Botany, v.40, n.214, p.599-607, 1989.

ASSOCIATION OF OFFICIAL SEED ANALYSTS. Seed vigor testing handbook. Lincoln, 1983. 93p. (Contribuition, 32). 
BARBEDO, A.S.C.; CÂMARA, F.L.A.; NAKAGAWA, J.; BARBEDO, C.J. População de plantas, método de colheita e qualidade de sementes de cenoura cultivar Brasília. Pesquisa Agropecuária Brasileira, v.35, n.8, p.1645-1652, 2000.

BENNETT, M.A.; BARR, A.J.; GRASSBAUGH, E.M.; EVANS, A.F. Seed vigour evaluation of su, se and sh2 sweet corn genotypes using the satturated salt accelerated aging (SSAA) test. In: CONGRESS OF International Seed Testing Association, 25., Pretoria, 1998. Abstracts. Pretoria: ISTA, 1998. p.92-93.

BEWLEY, J.D.; BLACK, M. Seeds: physiology of development and germination. New York: Plenum Press, 1994. 444p.

BHÉRING, M.C.; BARROS, D.I.; DIAS, D.C.F.S. Aplicação do vigor de sementes de melancia pelos testes de envelhecimento acelerado e deterioração controlada. Informativo ABRATES, v.11, n.2, p.204, 2001a.

BHÉRING, M.C.; BARROS, D.I.; DIAS, D.C.F.S.; NUNES, H.V. Testes para avaliação da qualidade fisiológica de sementes de berinjela. Informativo ABRATES, v.11, n.2, p.203, 2001 b.

BHÉRING, M.C.; DIAS, D.C.F.S.; GOMES, J.M.; BARROS, D.I. Métodos para avaliação do vigor de sementes de pepino. Revista Brasileira de Sementes, v.22, n.2, p.171-175, 2000. 
BRASIL. Ministério da Agricultura e Reforma Agrária. Regras para análise de sementes. Brasília: DNPV, 1992. 365p.

BUSTAMANTE, L.; SEDDON, M.G.; DON, R.; RENNIE, W.J. Pea seed quality and seedling emergence in the field. Seed Science and Technology, v.12, p.551-558, 1984.

CANO-RÍOS, P.; RAMÍREZ-ROSALES, G.; ORTEGÓN-PEREZ, J.; ESPARZAMARTÍNEZ, J.H.; RODRÍGUEZ-HERRERA, S. Análisis dialélico para vigor de semilla en melón. Agrociencia, v.34, n.3, p.337-342, 2000.

CARVALHO, M.V. Determinação do fator de correção para condutividade elétrica em função do teor de água de sementes de soja [Glycine max (L.) Merrill]. Jaboticabal, 1994. 36p. Monografia (Graduação) - Faculdade de Ciências Agrárias e Veterinárias, Universidade Estadual Paulista "Julio de Mesquita Filho".

CAVARIANI, C.; PIANA, Z.; TILLMANN, M.A.A.; MINAMI, K. Métodos de remoção da mucilagem e qualidade fisiológica de sementes de tomate (Lycopersicon esculentum, Mill.). Scientia Agricola, v.50, n.3, p.43-46, 1994.

COORDENADORIA DE ASSISTÊNCIA TÉCNICA INTEGRADA. Padrões de sementes para 1999/2000. Campinas, 1999. 6p. 
CORTES, P.M.; SPAETH, S.C. Potassium leakage from artificially aged pea (Pisum sativum L.) embryos during imbibition. Journal of Seed Technology, v.8, n.1, p.30-42, 1994.

CUSTODIO, C.C.; MARCOS FILHO, J. Potassium leachate test for the evaluation of soybean seed physiological quality. Seed Science and Technology, v.25, n.3, p.549-564, 1997.

DELOUCHE, J.C. Standardization of vigour testes. Journal of Seed Technology, v.1, n.2, p.75-85, 1976.

DELOUCHE, J.C.; BASKIN, C.C. Accelerated aging techniques for predicting the relative storability of seed lots. Seed Science and Technology, v.1, n.2, p.427-452, 1973.

DEMIR, I.; ELLIS, R.H. Development of pepper (Capsicum annuum) seed quality. Annals of Applied Biology, v.121, p.385-399, 1992.

DESWAL, D.P.; SHEORAN, I.S. A simple method for seed leakage measurement: applicable to single seeds of any size. Seed Science and Technology, v.21, n.1, p.179-185, 1993.

DIAS, D.C.F.S.; MARCOS FILHO, J.Testes de vigor baseados na permeabilidade das membranas celulares: I. Condutividade elétrica. Informativo Abrates, v.5, n.1, p.26-36, 1995. 
DIAS, D.C.F.S.; MARCOS FILHO, J.; CARMELLO, Q.A.C. Potassium leakage test for the evaluation of vigour in soybean seeds. Seed Science and Technology, v.25, n.1, p.7-18, 1996.

DIAS, D.C.F.S.; VIEIRA, A.N.; BHÉRING, M.C. Condutividade elétrica e lixiviação de potássio para avaliação do vigor de sementes de hortaliças: feijão-de-vagem e quiabo. Revista Brasileira de Sementes, v.20, n.2, p.408-413, 1998.

DUKE, S.H.; KAKEFUDA, G. Role of the testa in preventing cellular rupture during imbibition of legume seeds. Plant Physiology, v.67, n.2, p.449-456, 1981.

DURÁN, J.M.; CAMACHO, M.J.; RETAMAL, N. Um metodo rapido para la determinacion de calidadde semillas horticolas. Revista Científica Rural, v.2, n.1, p.1-7, 1997.

FERGUSON-SPEARS, J. Introduction to seed vigour testing. In: VAN DE VENTER, H.A. (Ed.). Seed vigour testing seminar. Zurich: International Seed Testing Association, 1995. p.1-10.

GIVELBERG, A.; HOROWITZ, M.; POLJAKOFF-MAYBER, A. Solute leakage from Solanum nigrum L. seeds exposed to high temperatures during imbibition. Journal of Experimental Botany, v.35, n.161, p.1754-1763, 1984. 
GLOBIRSON, D. The quality of lettuce seed harvested at different times after anthesis. Seed Science and Technology, v.9, p.861-866, 1981.

GRANQVIST, G.A. Leakage of cations from carrot seed lot. Acta Horticulturae, n.215, p.219-224, 1987.

GRAY, D. The effect of time to emergence on head weight and variation in head weight at maturity in lettuce (Lactuca sativa). Annals of Applied Biology, v.82, p.569-575, 1976.

GUIMARÃES, J.R.M.; MALAVASI, M.M.; LOPES, H.M. Definição do protocolo do teste de condutividade elétrica para avaliação do vigor de sementes de alface (Lactuca sativa L.). Informativo ABRATES, v.3, n.3, p.138, 1993.

HALLOIN, J.M. Solute loss deteriorated cottonseed: relationship between deterioration, seed moisture, and solute loss. Crop Science, v.15, n.1, p.11$15,1975$.

HAMPTON, J.G. Conductivity test. In: VAN DER VENTER, H.A. (Ed.). Seed vigour testing seminar. Zurich: International Seed Testing Association, 1995. p.10-28.

HAMPTON, J.G.; COOLBEAR, P. Potencial versus actual seed performance can vigour testing provide an answer? Seed Science and Technology, v.18, p.215-228, 1990. 
HAMPTON, J.G.; JOHNSTONE, K.A.; EUA-UMPON, V. Bulk conductivity test variables for mungbean, soybean and French bean seed lots. Seed Science and Technology, v.20, n.3, p.677-686, 1992.

HAMPTON, J.G.; LUNGWANGWA, A.L.; HILL, K.A. The bulk conductivity test for Lotus seed lots. Seed Science and Technology, v.22, n.1, p.177-180, 1994.

HAMPTON, J.G.; TEKRONY, D.M. Handbook of vigor test methods. Zurich: ISTA, 1995. 117p.

HEPBURN, H.A.; POWELL, A.A.; MATTHEWS, S. Problems associated with the routine application of electrical conductivity measurements of individual seeds in the germination testing of peas and soybeans. Seed Science and Technology, v.12, n.2, p.403-413, 1984.

IDIARTE, H.G. Relação do envelhecimento acelerado na qualidade fisiológica de semente de cebola. Piracicaba, 1995. 84p. Dissertação (Mestrado) Escola Superior de Agricultura "Luiz de Queiroz", Universidade de São Paulo.

INTERNATIONAL SEED TESTING ASSOCIATION. Handbook of vigour test methods. 3.ed. Zurich: 1995. 117p. 
JIANHUA, Z.; McDONALD, M.B. The satured salt accelerated aging test for small seeded crops. Seed Science and Technology, v.25, p.123-131, 1996.

KRISHNASAMY, V.; RAMARAJPALANIAPPAN, M.S.M.G. Electrical conductivity of seed leachate in tomato and brinjal. South Indian Horticulture, v.37, n.5, p.303-304, 1989.

KRZYZANOWSKI, F.C.; FRANÇA NETO, J.B.; HENNING A.A. Relato dos testes de vigor disponíveis para grandes culturas. Informativo ABRATES, v.1, n.2, p.15-50, 1991.

LARSEN, S.U.;POVLSEN, F.V.; ERIKSEN, E.N.; PEDERSEN, H.C. The influence of seedvigour on field performance and the evaluation of the applicabilityof the controlled deterioration vigour test in oil seed rape (Brassica napus L.) and pea (Pisum sativum L.). Seed Science and Technology, v.26, n.3, p. 627-641, 1998.

LEOPOLD, A.C. Temperature effects on soybean imbibition and leakage. Plant Physiology, v.65, n.4, p.1096-1098, 1980.

LIMA, D. Avaliação da viabilidade e vigor de sementes de cebola (Allium cepa L.). Pelotas, 1993. 61p. Dissertação (M.S.) - Universidade Federal de Pelotas. 
LIMA, W.A.A.; DIAS, D.C.F.S.; BACCO, M.G. Teste de envelhecimento acelerado na avaliação do vigor de sementes de quiabo. Informativo ABRATES, v.7, n.1/2, p.179, 1997.

LOEFFLER, T.M. The bulk conductivity test as an indicator of soybean seed quality. Lexington, 1981. 181p. Dissertation (M.S.) - University of Kentucky.

LOEFFLER, T.M.; TEKRONY, D.M.; EGLI, D.B. The bulk conductivity test as an indicator of soybean seed quality. Journal of Seed Technology, v.12, n.1, p.37-53, 1988.

LOOMIS, E.L.; SMITH, O.E. The effect of artificial aging on the concentration of $\mathrm{Ca}, \mathrm{Mg}, \mathrm{Mn}, \mathrm{K}$ and $\mathrm{Cl}$ in imbibing cabbage seed. Journal of the American Society of Horticultural Science, v.105, n.5, p.647-650, 1980.

LOTT, J.N.A.; CAVDEK, V.; CARSON, J. Leakage of K, Mg, Cl, Ca and Mn from imbibing seeds, grains and isolates seed parts. Seed Science Research, v.1, n.4, p.229-233, 1991.

MARCOS FILHO, J. Teste de envelhecimento acelerado. In: KRZYZANOWSKI, F.C.; VIEIRA, R.D.; FRANÇA NETO, J.B. (Ed.). Vigor de sementes: conceitos e testes. Londrina: ABRATES, 1999a. cap.3, p.1-24.

MARCOS FILHO, J. Testes de vigor: importância e utilização. In: KRZYZANOWSKI, F.C.; VIEIRA, R.D.; FRANÇA NETO, J.B. (Ed.). Vigor de sementes: conceitos e testes. Londrina: ABRATES, 1999b. cap.1, p.1-21. 
MARCOS FILHO, J.; CÍCERO, S.M.; SILVA, W.R. Avaliação da qualidade das sementes. Piracicaba: FEALQ, 1987. 230p.

MARCOS FILHO, J.; NOVEMBRE, A.D.C.; CHAMMA, H.M.C.P. Testes de envelhecimento acelerado e deterioração controlada para avaliação do vigor de sementes de soja. Scientia Agricola, v.58, n.2, p.421-426, 2001.

MARCOS FILHO, J.; AMORIM, H.V.; SILVAROLA, M.B.; PESCARIN, H.M.C. Relação entre germinação, vigor e permeabilidade das membranas celulares durante a maturação de sementes de soja. In: SEMINÁRIO NACIONAL DE PESQUISA DE SOJA, 2., Brasília, 1981. Anais. Londrina: EMBRAPA/CNPSo, 1982. p.676-683.

MARCOS FILHO, J.; SILVA, W.R.; NOVEMBRE, A.D.L.C.; CHAMMA, H.M.C.P. Estudo comparativo de métodos para a avaliação da qualidade fisiológica de sementes de soja, com ênfase no teste de condutividade elétrica. Pesquisa Agropecuária Brasileira, v.25, n.12, p.1805-1815, 1990.

MARTINS, L.; SPINOLA, M.C.M.; CALIARI, M.F.; TESSARIOLI NETO, J. Comparação entre métodos para avaliação do vigor de sementes de cenoura (Daucus carota L.). In: SEMINÁRIO PANAMERICANO DE SEMILLAS, 15., Gramado, 1996. Anais. Gramado: CESM, ELAS, 1996. p.20.

MATTHEWS, S. Controlled deterioration: a new vigour test for crop seeds. In: HEBBLETWAITE, P. D. (Ed.) Seed production. London: Butterworths, 1980. p.647-660. 
MATTHEWS, S.; BRADNOCK, W.T. The detection of seed samples of wrinkleseed peas (Pisum sativum L.) of potentially low planting. Proceedings of the International Seed Test Association, v.32, p.553563, 1967.

McDONALD, M.B. Improving our undertandingof vegetable and flower seed quality. Seed Technology, v.20, n.2, p.121-124, 1998.

McDONALD, M.B.; WILSON, D.O. An assessment of the standardization and ability of the ASA-610 to rapidly predict potencial soybean germination. Journal of Seed Technology, v.4, n.2, p.1-11, 1979.

McKERSIE, B.D.; STINSON, R.H. Effect of dehydration on leakage and membrane structure in Lotus corniculatus L. seeds. Plant Physiology, v.66, n.2, p.316-320, 1980.

MELLO, S.C.; SPINOLA, M.C.M.; MINAMI, K. Métodos de avaliação da qualidade fisiológica de sementes de brócolos. Scientia Agricola, v.56, n.4, p. 1151-1155, 1999.

MENDONÇA, E.A.F.; RAMOS, N.P.; FESSEL, S.A.; SADER, R. Teste de deterioração controlada em sementes de brocoli (Brassica oleraceae L.) var. italica. Revista Brasileira de Sementes, v.22, n.1, p.280-287, 2000. 
MENEZES, N.L.; SANTOS, C.M.R.; NUNES, E.P. Germinação e vigor de sementes de rabanete influenciados pelos potenciais osmóticos induzidos por cloreto de sódio e pH. Informativo ABRATES, v.11, n.2, p.189, 2001. /Apresentado ao 12. Congresso Brasileiro de Sementes, Curitiba, 2001/.

MIGUEL, M.V.C. Avaliação do potencial fisiológico de sementes de milho através do teste de lixiviação de potássio. Piracicaba, São Paulo, 2001. 113 p. Tese (Doutorado) - Escola Superior de Agricultura "Luiz de Queiroz", Universidade de São Paulo.

MINAMI, K.; CARDOSO, A.I.I.; COSTA, F.; DUARTE, F.R. Efeito do espaçamento sobre a produção em rabanete. Bragantia, v.57, n.1, p.146$149,1998$.

MOSS, G.I.; MULLET, J.H. Potassium release and seed vigour in germination bean (Phaseolus vulgaris L.) seed as influenced by temperature over the previous five generations. Journal of Experimental Botany, v.33, n.137, p.1147-1160, 1982.

MULLETT, J.H.; CONSIDINE, J.A. Potassium release and uptake in germination legume seeds in relation to seed condition and germination environment. Journal of Experimental Botany, v.31, p.151-162, 1980.

MULLETT, J.H.; WILKINSON, R.I. The relationship between amounts of electrolyte lost on leaching seeds of Pisum sativum and some parameters of plant growth. Seed Science and Technology, v.7, n.3, p.393-398, 1979. 
MURPHY, J.B.; NOLAND, T.L. Temperature effects on seed imbibition and leakage mediated by viscosity and membranes. Plant Physiology, v.69, n.2, p.428-431, 1982.

NASCIMENTO, W.M.; BARROS, B.C.G.; PESSOA, H.B.S.V. Teste de envelhecimento acelerado em sementes de tomate. Revista Brasileira de Sementes, v.15, n.2, p.251-253, 1993.

NOVEMBRE, A.D.L.C.; DIAS, D.C.F.S.; CHAMMA, H.M.C.P.; MARCOS FILHO, J. Estudo da metodologia dos testes de envelhecimento acelerado e de condutividade elétrica para sementes de tomate. Informativo ABRATES, v.3, n.3, p.140, 1995.

OLIVEIRA, J.A. Correlação entre a evolução de hexanal e de aldeídos totais, a lixiviação de íons e o potencial de germinação de sementes de soja (Glycine $\max$ (L.) Merrill). Viçosa, 1990. 79p. Dissertação (M.S.) Universidade Federal de Viçosa.

OLUOCH, M.O.; WEBAUM, G.E. Effect of postharvest washing and poststorage priming on viability and vigour of six-year-old muskmelon (Cucumis melo L.) seeds from eight stages of development. Seed Science and Technology, v.24, p.195-209, 1996.

PANOBIANCO, M.; MARCOS FILHO, J. Comparação entre métodos para avaliação da qualidade fisiológica de sementes de pimentão. Revista Brasileira de Sementes, v.20, n.2, p.306-310, 1998. 
PANOBIANCO, M.; MARCOS FILHO, J. Comparação entre métodos para avaliação da qualidade fisiológica de sementes de pimentão. Informativo ABRATES, v.9, n.1/2, p. 134, jul./ago. 1999.

PANOBIANCO, M.; MARCOS FILHO, J. Avaliação do potencial fisiológico de sementes de tomate através dos testes de germinação e vigor. Informativo ABRATES, v.11, n.2, p.179, res.264, 2001a. /Apresentado ao 12. Congresso Brasileiro de Sementes, Curitiba, 2001/.

PANOBIANCO, M.; MARCOS FILHO, J. Evaluation of the physiological potential of tomato seeds by germination and vigor tests. Seed Technology, v.23, n.2, p.151-161, 2001 b.

PANOBIANCO, M.; VIEIRA, R.D. Electrical conductivity of soybean soaked seeds: I - Effect of genotype. Pesquisa Agropecuária Brasileira, v.31, n.9, p.621-627, 1996.

PANOBIANCO, M.; VIEIRA, R.D.; KRZYZANOWSKI, F.C.; FRANÇA NETO, J.B. Electrical conductivity of soybean seed and correlation with seed coat lignin content. Seed Science and Technology, v.27, n.3, p.945-949, 1999.

PENARIOL, A.L. Efeito do teor de água de sementes de soja sobre os resultados do teste de condutividade elétrica. Jaboticabal, 1997. 73p. Dissertação (Mestrado) - Faculdade de Ciências Agrárias e Veterinárias, Universidade Estadual Paulista “Julio de Mesquita Filho". 
PERRY, D.A. Report of vigour test committee 1977-1980. Seed Science and Technology, v.9, n.1, p.115-126, 1981.

PIANA, D.A.; TILLMANN, M.A.A.; MINAMI, K. Avaliação da qualidade fisiológica de sementes de cebola e sua relação com a produção de mudas vigorosas. Revista Brasileira de Sementes, v.17, n.2, p.149-153, 1995.

POWELL, A.A. Cell membranes and seed leachate conductivity in relation to the quality of seed for sowing. Journal of Seed Technology, v.10, n.2, p.81$100,1986$.

POWELL, A.A. Seed vigour and field establishment. Advances in Research and Technology of Seeds, v.11, p.29-61, 1988.

POWELL, A.A. The controlled deterioration test. In: INTERNATIONAL SEED TESTING ASSOCIATION. Seed vigour testing seminar. Zurich, 1995. p.73-87.

POWELL, A.A.; FERGUSON, A.J.; MATTHEWS, S. Identification of vigour differences among combining pea (Pisum sativum) seed lots. Seed Science and Technology, v.25, n.3, p.443-464, 1997.

POWELL, A. A.; MATTHEWS, S. The influence of testa condition on the imbibition and vigour of pea seeds. Journal of Experimental Botany, v.30, n.114, p.193-197, 1979. 
POWELL, A. A.; MATTHEWS, S. Evaluation of controlled deterioration, a new vigour test for small seeds vegetables. Seed Science and Technology, v.9, p.633-640, 1981.

POWELL, A. A.; MATTHEWS, S. Prediction of the storage potential of onion seed under commercial storage conditions. Seed Science and Technology, v.12, n.2, p.641-647, 1984.

RAMOS, N.P.; OBANDO FLOR, E.P.; MENDONÇA, E.A.F. de; MINAMI, K. Envelhecimento acelerado em sementes de rúcula (Eruca sativa L.). Revista Brasileira de Sementes, v.26, n.1, p.98-103, 2004.

RIBEIRO, F.C.; CARVALHO, N.M. The saturated salt accelerated ageing (SSAA) method seems to act too leniently on carrot (Daucus carota L.), lettuce (Lactuca sativa L.), and brocoli (Brassica oleraceae var. Italica, Plenck) seeds germination. In: CONGRESS OF THE INTERNATIONAL SEED TESTING ASSOCIATION, 26., Angers, 2001. Angers: ISTA, 2001. p.41-42.

RODO, A.B.; MARCOS FILHO, J. Procedimento alternativo para o teste de envelhecimento acelerado em sementes de cebola. Informativo ABRATES, v.11, n.2, p.183, 2001a. /Apresentado ao 12. Congresso Brasileiro de Sementes, Curitiba, 2001/. 
RODO, A.B.; MARCOS FILHO, J. Teste de lixiviação de potássio para avaliação rápida do potencial fisiológico de sementes de cebola. Informativo ABRATES, v.11, n.2, p.183, 2001b. /Apresentado ao 12. Congresso Brasileiro de Sementes, Curitiba, 2001/.

RODO, A.B.; PANOBIANCO, M.; MARCOS FILHO, J. Metodologia alternativa do teste de envelhecimento acelerado para sementes de cenoura. Scientia Agricola, v.57, n.2, p.289-292. 2000.

RODO, A.B.; TILLMANN, M.A.A.; VILLELA, F.A.; SAMPAIO, N.V. Teste de condutividade elétrica em sementes de tomate. Revista Brasileira de Sementes, v.20, n.1, p.29-38, 1998a.

RODO, A.B.; TILLMANN, M.A.A.; VILLELA, F.A. Testes de vigor na avaliação da qualidade fisiológica de sementes de tomate. Revista Brasileira de Sementes, v.20, n.1, p.23-28, 1998b.

ROSSETO, C.A.V.; FERNANDEZ, E.M.; MARCOS FILHO, J. Metodologias de ajuste do grau de umidade e comportamento das sementes de soja no teste de germinação. Revista Brasileira de Sementes, v.17, n.2, p.171-178, 1995.

SÁ, M.E. Condutividade elétrica em sementes de tomate (Lycopersicon lycopersicum L.). Scientia Agricola, v.56, n.1, p.13-19, 1999. 
SADER, R.; MENDONÇA, E.A.F.; RAMOS, N.P.; FESSEL, S.A. Teste de deterioração controlada em sementes de brocoli (Brassica oleracea L. var. itálica). Informativo ABRATES, v.11, n.2, p.175, 2001. /Apresentado ao 12. Congresso Brasileiro de Sementes, Curitiba, 2001/.

SAMAD, L.M.A.; PEARCE, R.S. Leaching of ions, organic molecules, and enzymes from seeds of peanut (Arachis hypogea L.) imbibing without testas or with intact testas. Journal of Experiental Botany, v.29, n.113, p.14711478, 1978.

SCHIMIDT, D.H.; TRACY, W.F. Duration of imbibition affects seed leachate conductivity in sweet corn. HortScience, v.24, n.2, p.346-347, 1989.

SHORT, G.E.; LACY, M.L. Carbohydrate exudation from pea seeds: effect of cultivar, seed age, seed color, and temperature. Phytopathology, v.66, n.2, p.182-187, 1976.

SIDDIQUE, M.A.; GOODWIN, P.B. Conductivity measurements on single seeds to predict the germinability of French beans. Seed Science and Technology, v.13, n.3, p.643-652, 1985.

SILVA, M.A.S.; TORRES, S.B.; CARVALHO, I.M.S. Teste de envelhecimento acelerado em sementes de maxixe (Cucumis anguria L.). Revista Brasileira de Sementes, v.20, n.1, p.212-214, 1998. 
SIMON, E.W.; MATHAVAN, S. The time-course of leakage from imbibing seeds of different species. Seed Science and Technology, v.14, n.1,p.9-13, 1986.

SIMON, E.W.; RAJA HARUN, R.M. Leakage during seed imbibition. Journal of Experimental Botany, v.23, n.77, p.1076-1085. 1972.

STYER, R.C.; CANTLIFE, D.J. Changes in seed structure and composition during development and their effects on leakage in two endosperm mutants of sweet corn. Journal of the American Society for Horticultural Science, v.108, n.5, p.721-728, 1983.

STRYDOM, A.; VAN DE VENTER, H.A. Comparison of seed vigour tests for cabbage (Brassica oleracea L. var. capitata L.). Seed Science and Technology, v.26, n.3, p.579-585, 1998.

TAO, J.K. Factors causing variations in the conductivity test for soybean seeds. Journal of Seed Technology, v.3, n.1, p.10-18, 1978.

TAYLOR, A.G.; LEE, S.S.; BERESNIEWICZ, M.M.; PAINE, D.H. Aminoacid leakage from aged vegetable seeds. Seed Science and Technology, v.23, p.113-122, 1995. 
TEBALDI, N.D.; SADER, R.; BIRUEL, R.P.; SCALON, N.J.O.; BALLARIS, A.L.; GAVIOLI, E. Determinação do tempo e da temperatura para o teste de envelhecimento acelerado de sementes de brócolos (Brassica oleracea L.) var. italica Plenk. In: CONGRESSO BRASILEIRO DE SEMENTES, 11., Foz do Iguaçu, 1999. Resumos. Curitiba: ABRATES, 1999. p.120.

TEKRONY, D.M. Seed vigour testing - 1982. Journal of Seed Technology, v.8, n.1, p.55-60, 1983.

TEKRONY, D.M. Accelerated aging. In: VAN DE VENTER, H.A. (Ed.). Seed vigour testing seminar. Copenhagen: The International Seed Testing Association, 1995. p.53-72.

TOMES, L.T.; TEKRONY, D.M.; EGLI, D.B. Factors influencing the tray accelerated aging test for soybean seed. Journal of Seed Technology, v.12, n.1, p.24-36, 1998.

TORRES, S.B. Qualidade fisiológica de sementes de pimentão (Capsicum annuum L.) através do teste de estresse hídrico. Revista Brasileira de Sementes, v.18, n.2, p.246-250, 1996.

TORRES, S.B. Comparação entre diferentes testes de vigor e a correlação com a emergência no campo de sementes de cebola. Revista Brasileira de Sementes, v.20, n.1, p.65-69, 1998. 
TORRES, S.B. Métodos para avaliação do potencial fisiológico de sementes de melão. Piracicaba, 2002. 103p. Tese (Doutorado) - Escola Superior de Agricultura "Luiz de Queiroz", Universidade de São Paulo.

TORRES, S.B.; MINAMI, K. Qualidade fisiológica de sementes de pimentão. Scientia Agricola, v.57, n.1, p.109-112, 2000.

TORRES, S.B.; CASEIRO, R.F.; RODO, A.B.; MARCOS FILHO, J. Testes de vigor em sementes de maxixe (Cucumis anguria L.) com ênfase no teste de condutividade elétrica. Revista Brasileira de Sementes, v.20, n.2, p.480483, 1998.

TORRES, S.B.; SILVA, M.A.S.; CARVALHO, I.M.S.; QUEIRÓZ, M.A. Correlação entre testes de vigor em sementes de maxixe. Pesquisa Agropecuária Brasileira, v.34, n.6, p.1075-1080, 1999.

TRAWATHA, S.E.; STEINER, J.J.; BRADFORD, K.J. Laboratory vigour tests used to predict pepper seedling field emergence performance. Crop Science, v.30, p.713-717, 1990.

VIEIRA, R.D.; CARVALHO, N.M. de. Testes de vigor em sementes. Jaboticabal: FUNEP, 1994. 164p.

VIEIRA, R.D.; KRZYZANOWSKI, F.C. Teste de condutividade elétrica. In: KRZYZANOWSKI, F.C.; VIEIRA, R.D.; FRANÇA NETO, J.B. (Ed.). Vigor de sementes: conceitos e testes. Londrina: ABRATES, 1999. cap.4, p.1-26. 
VIEIRA, R.D.; PANOBIANCO, M.; LEMOS, L.B.; FORNASIERI FILHO, D. Efeito de genótipos de feijão e de soja sobre os resultados da condutividade elétrica de sementes. Revista Brasileira de Sementes, v.18, n.2, p.220224, 1996.

VIEIRA, R.D.; MINOHARA, L.; PANOBIANCO, M.; BERGAMASCHI, M.C.M.; MAURO, A.O. Comportamento de cultivares de soja quanto a qualidade fisiológica de sementes. Pesquisa Agropecuária Brasileira, v.33, n.2, p.123-130, 1998.

WANG, Y.R.; HAMPTON, J.G; HILL, M.J. Red clover vigour testing: effects of three test variables. Seed Science and Technology, v.22, n.1, p.99-105, 1994.

WOODSTOCK, L.W. Seed imbibition: a critical period for successful germination. Journal of Seed Technology, v.12, n.1, p.1-15, 1988.

WOODSTOCK, L.W.; FURMAN, K.; LEFFLER, H.R. Relationship between weathering deterioration and germination, respiratory metabolism, and mineral leaching from cottonseeds. Crop Science, v.25, n.3, p.459-466, 1985.

WURR, D.C.E.; FELLOUS, J.R. The effect of time of seedling emergence of crisp lettuce on time of maturity. Journal of Horticultural Science, v.58, n.4, p.561-566, 1983. 
ZHANG, T.; HAMPTON, J.G. The controlled deterioration test induce dormancy in swede (Brassica napus var. naprobrassica) seed. Seed Science and Technology, v.27, n.3, p. 1033-1036, 1999.

ZONTA, E.P.; MACHADO, A.A. Sistema de análise estatística para microcomputadores-SANEST. Pelotas: UFPel, 1984. (Registro SEI n.06606-0, categoria AO). 